University of Nebraska - Lincoln

DigitalCommons@University of Nebraska - Lincoln

Publications from USDA-ARS / UNL Faculty

U.S. Department of Agriculture: Agricultural

Research Service, Lincoln, Nebraska

6-28-2013

New pieces of the Trichinella puzzle

Edoardo Pozio

Dante S. Zarlenga

Follow this and additional works at: https://digitalcommons.unl.edu/usdaarsfacpub

This Article is brought to you for free and open access by the U.S. Department of Agriculture: Agricultural Research Service, Lincoln, Nebraska at DigitalCommons@University of Nebraska - Lincoln. It has been accepted for inclusion in Publications from USDA-ARS / UNL Faculty by an authorized administrator of DigitalCommons@University of Nebraska - Lincoln. 
Invited Review

\title{
New pieces of the Trichinella puzzle
}

\author{
Edoardo Pozio ${ }^{\mathrm{a}, *}$, Dante S. Zarlenga ${ }^{\mathrm{b}}$ \\ ${ }^{a}$ European Union Reference Laboratory for Parasites, Istituto Superiore di Sanità, viale Regina Elena 299, 00161 Rome, Italy

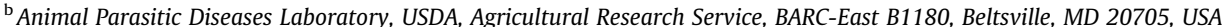

\section{A R T I C L E I N F O}

\section{Article history:}

Received 11 April 2013

Received in revised form 27 May 2013

Accepted 29 May 2013

Available online 28 June 2013

\section{Keywords:}

Trichinella

Taxonomy

Phylogeny

Biology

Epidemiology

Genomics

Proteomics

\begin{abstract}
A B S T R A C T
Contrary to our understanding of just a few decades ago, the genus Trichinella now consists of a complex assemblage of no less than nine different species and three additional genotypes whose taxonomic status remains in flux. New data and methodologies have allowed advancements in detection and differentiation at the population level which in turn have demonstrably advanced epidemiological, immunological and genetic investigations. In like manner, molecular and genetic studies have permitted us to hypothesise biohistorical events leading to the worldwide dissemination of this genus, and to begin crystalising the evolution of Trichinella on a macro scale. The identification of species in countries and continents otherwise considered Trichinella-free has raised questions regarding host adaptation and associations, and advanced important findings on the biogeographical histories of its members. Using past reviews as a backdrop, we have ventured to present an up-to-date assessment of the taxonomy, phylogenetic relationships and epidemiology of the genus Trichinella with additional insights on host species, survival strategies in nature and the shortcomings of our current understanding of the epidemiology of the genus. In addition, we have begun compiling information available to date on genomics, proteomics, transcriptomics and population studies of consequence in the hope we can build on this in years to come.
\end{abstract}

(c) 2013 Australian Society for Parasitology Inc. Published by Elsevier Ltd. All rights reserved.

\section{Introduction}

Nematodes of the genus Trichinella are zoonotic parasites with a cosmopolitan distribution and which infect over 2,500 people annually (Murrell and Pozio, 2011). This nematode was discovered 177 years ago in the United Kingdom during an autopsy on a woman of Italian origin and was named Trichina spiralis Owen, 1835. At first, this parasite was considered only a scientific curiosity. However, in 1860 , the pathologist Zenker demonstrated its pathogenicity to humans (Campbell, 1983). This heightened its interest for the scientific community. This was followed in 1895 with a change in name of the genus to Trichinella Railliet, 1895 as the designation Trichina had been utilised for a genus of Diptera since 1830 (Gould, 1970). At that time and for the next hundred years, the large number of human infections due to the consumption of domestic pork products focused the attention of veterinarians, physicians and public health authorities on the important role of pigs in the natural cycle of this nematode (Campbell, 1983). However, the basic science related to the biology and epidemiology of these zoonotic nematodes was not sufficiently studied.

Even amidst a strong reduction in Trichinella infections in domestic pigs and humans over the last decade, this parasite group continues to represent a "black mark" for the pig industry. This re-

\footnotetext{
* Corresponding author. Tel.: +39 064990 2304; fax: +39 0649903561.

E-mail address: edoardo.pozio@iss.it (E. Pozio).
}

sults from consumer perceptions of ingesting infected meat, accidentally introduced into the food chain. However, even if Trichinella infections have never been documented in pigs raised in high containment facilities, testing for Trichinella is still required for pork products within the international trade market. This additional testing and product validation can in many cases escalate the price of imported meats making them less competitive at neighbourhood food stores.

In addition to persistent economic and sanitary interests, the genus Trichinella represents a very interesting model to study biological mechanisms due its uniqueness among nematodes and its broad host spectrum which includes more than 100 species of mammals, birds and reptiles (Pozio, 2005). For these reasons, the scientific literature has become substantially enriched in recent times. The aim of this review is to amalgamate past knowledge with new data on the taxonomy, phylogeny, genome and epidemiology of Trichinella parasites, and provide a comprehensive view of our understanding of the genus to date. However, as with all scientific research, each contemporary piece of the "Trichinella puzzle" will be met with new questions to be addressed.

\section{Taxonomy and epidemiology}

For more than 130 years after its discovery, Trichinella spiralis was considered the only species in the genus even amidst increasing numbers of studies showing substantial biological variability 
among isolates originating from different geographical regions and hosts (Dick, 1983). In 1972, three new species, named Trichinella nativa, Trichinella nelsoni and Trichinella pseudospiralis, were described (Britov and Boev, 1972; Garkavi, 1972). Twenty years later, the genus was revised and a new species, designated Trichinella britovi, was identified in addition to three other genotypes, Trichinella T5, T6 and T8 (Pozio et al., 1992). During the last 12 years, the increasing number of investigations in different geographical regions and hosts coupled with the availability of new and highly sensitive molecular techniques has allowed the description of four new species (Trichinella murrelli, Trichinella papuae, Trichinella zimbabwensis and Trichinella patagoniensis) and one new genotype (Trichinella T9) (Pozio and Zarlenga, 2005; Krivokapich et al., 2012). The distribution of each Trichinella taxon are shown in Figs. 1 and 2.

Today, two main clades have been recognised in the genus Trichinella; one that encompasses species that encapsulate in host muscle tissues following muscle cell reprogramming, and a second that does not encapsulate (Zarlenga et al., 2006; Pozio et al., 2009a). The species and genotypes of the first clade parasitise only mammals. Among the three species that comprise the second clade, one infects mammals and birds (T. pseudospiralis) and two parasitise mammals and reptiles (T. papuae and T. zimbabwensis) (Pozio et al., 2009a).

The existence of two clades within the genus Trichinella is also supported by the geographical distribution of the species. In the encapsulated clade, each recognised species occurs within its own geographical area which is different from that of the other species in the clade (see Figs. 1A and 2A and B). The only exception is $T$. spiralis which likely originated in eastern Asia and has been passively spread to other continents (i.e., Europe, North and South America, Hawaii and New Zealand) via the transportation of pigs and pig products by humans. It follows therefore, that $T$. spiralis is periodically detected in mixed infections in areas where other species of the encapsulated clade circulate (e.g., T. spiralis and T. britovi in Europe; T. spiralis and T. nativa in Europe and North America; T. spiralis and T. murrelli in North America) (Pozio et al., 1997a; Oivanen et al., 2002; Liciardi et al., 2009; http://www. iss.it/site/Trichinella/scripts/). Mixed infections not involving $T$. spiralis have also been detected; however, these occur in the contact zones between distribution areas of two species or their related genotypes, (e.g., T. britovi and T. nativa in Europe; Trichinella T8 and T. nelsoni in South Africa) (Malakauskas et al., 2007; Marucci et al., 2009; Airas et al., 2010).

The distribution of Trichinella spp. belonging to the encapsulated or the non-encapsulated clades in most instances are confined geographically. In other words, other than for T. spiralis, there are few contact zones (see Sections 2.1.2-2.1.6) among the encapsulated species. In like manner, few if any contact zones exist among the non-encapsulated species (Figs. 1 and 2). However, this seems not to be the case when examining contact zones between parasites of different clades. Trichinella spp. belonging to the two clades have been observed to coexist independently in the same geographical region (e.g., T. pseudospiralis and either T. spiralis, $T$. britovi or T. nativa in the Palearctic region; T. zimbabwensis and either T. nelsoni or Trichinella T8 in Africa south of the Sahara; $T$. papuae and T. spiralis in south eastern Asia).

\subsection{The encapsulated clade}

\subsubsection{Trichinella spiralis (Owen, 1835)}

This was the first species discovered and has been the best characterised due to its importance as a cause of human disease and as a model for basic biological research investigations. This was due in large part to the relatively high prevalence of $T$. spiralis in domestic and sylvatic animals and to its high infectivity for laboratory animals (Pozio and Murrell, 2006). This species is well adapted to domestic and wild pigs (Sus scrofa) which represent the most important reservoir for this parasite. Furthermore, $T$. spiralis has been detected frequently in carnivores and rodents, and less so in horses and armadillos (International Trichinella Reference Centre (ITRC) http://www.iss.it/site/Trichinella/scripts/; Table 1). The core distribution area of $T$. spiralis extends to eastern Asia (China, Laos, Myanmar, South Korea, Thailand, Vietnam). Trichinella spiralis is widespread throughout Europe, Egypt, North America (Mexico and USA) and South America (Argentina, Bolivia and Chile), Hawaii and New Zealand (Fig. 1A). A previous focus of T. spiralis in Canada seems to have been eradicated inasmuch as $T$. spiralis has not been isolated from domestic or wild animals from this region in over 40 years (Gajadhar and Forbes, 2010). In T. spiralis endemic areas, the number of infected domestic and wild animals tends to coincide with the integrity of pig husbandry and wildlife management (Rafter et al., 2005; Burke et al., 2008; Blaga et al., 2009; Pozio et al., $2009 b)$. The genetic variability of the $T$. spiralis population from eastern Asia is substantially higher than that observed in other geographical locations, suggesting the recent introduction of this species into Europe and the Americas (Zarlenga et al., 2006; Rosenthal et al., 2008; La Rosa et al., 2012). The first appearances of $T$. spiralis in North and South America and New Zealand are likely to have been the result of passive introduction with domestic pigs and/or synanthropic rats during colonisations by European immigrants. However, it is more difficult to assign a time frame to the origins of $T$. spiralis in western Europe which can be linked to the migration of brown rats (Rattus norvegicus) from eastern Asia in the Middle Ages (Yoshida, 1980) and/or the introduction of domestic pigs or pig-derived products from the Far East. Early origins for $T$. spiralis in Europe are not supported because this pathogen is not widespread among wildlife. Rather, $T$. britovi is the most prevalent species in Europe. Among the 47 countries that comprise the European continent, the environmental conditions of seven $(14.9 \%)$ countries are not well suited for circulating Trichinella (small islands or city states), and no epidemiological information is available for three $(6.4 \%)$ of these countries. Trichinella spiralis has been detected in animals in 21 (44.7\%) countries, whereas T. britovi circulates among animals in 35 (74.5\%) countries. Inasmuch as domestic pork is the main source of trichinellosis, T. spiralis still accounts for most human infections worldwide.

\subsubsection{Trichinella nativa Britov and Boev, 1972 and the genotype Trichinella T6 Pozio et al., 1992}

Trichinella nativa circulates in the arctic and subarctic areas of the Holarctic. The southern distribution boundary has been identified between the isotherms $-5-\left(-4{ }^{\circ} \mathrm{C}\right)$ in January (Shaikenov and Boev, 1983; Shaikenov, 1992; Pozio et al., 1998; Pozio and La Rosa, 2000) (Fig. 2A). However, some T. nativa isolates have been collected from red foxes hunted south of the $-5-\left(-4{ }^{\circ} \mathrm{C}\right)$ isotherm in Germany and Poland, suggesting: (i) a broad north-to-south migratory range for the red fox; (ii) recent east-to-west migration patterns of the raccoon dog (Nyctereutes procyonoides) in Europe (Pannwitz et al., 2010); (iii) passive introduction of T. nativa by hunters who dispose of infected game meat from arctic regions; or (iv) a glacial relict (Chmurzyńska et al., in press). As previously reported, $T$. nativa circulates among wild animals, predominantly carnivores (both terrestrial and marine; http://www.iss.it/site/ Trichinella/scripts/; Table 1). On rare occasions, T. nativa has been found in wild boars and twice in domestic animals (a pig and a dog from China) (Gasser et al., 1998). A biological peculiarity of this species is its ability to survive in frozen muscles of carnivores for several years (Dick and Pozio, 2001). This character is unique to the carnivorous host wherein freeze resistance is lost when larvae parasitise laboratory animals (rodents) (Dick and Pozio, 2001). People living in the arctic areas (e.g., Inuit) and those who hunt 

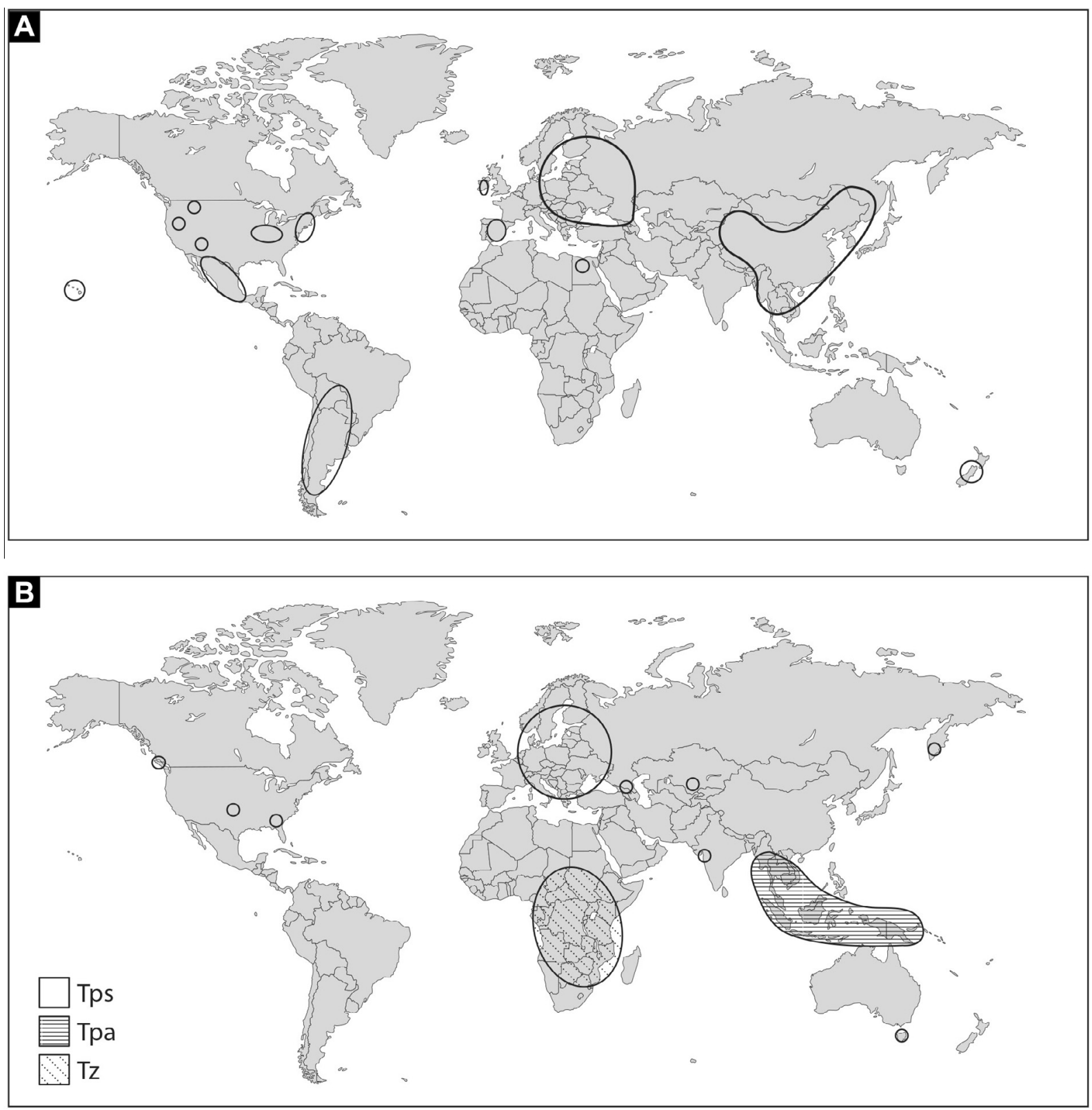

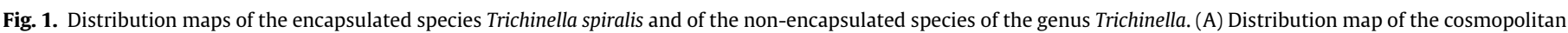

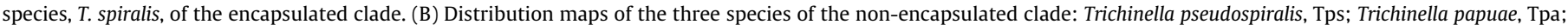
and Trichinella zimbabwensis, Tz.

in these regions are at risk of acquiring $T$. nativa infection by the consumption of raw or semi-raw meat from bears and walruses (Serhir et al., 2001; Møller et al., 2005; Anonymous, 2006; Houzé et al., 2009). Indeed, even igunaq, a form of cured or aged walrus meat, can contain viable T. nativa larvae (Serhir et al., 2001). To address this risk, a community-based program was established to test walruses hunted by the Inuit people in Quebec (Proulx et al., 2002). Trichinellosis has not been documented among the Inuit communities participating in this control project (Larrat et al., 2012).

The genotype Trichinella T6 is closely related to T. nativa as demonstrated by successful interbreeding under experimental conditions (La Rosa et al., 2003a). Similar to T. nativa, the natural hosts are carnivorous mammals. This genotype has been detected in Canada (British Columbia, Ontario, Manitoba, Northwest Territories, Nunavut, Yukon Territory) and the United States (Alaska, Montana, Idaho, Pennsylvania) (La Rosa et al., 2003b; Reichard et al., 2008; Gajadhar and Forbes, 2010) (Fig. 2B). Natural hybrids between Trichinella $\mathrm{T} 6$ and $T$. nativa have been detected in nature, suggesting a recent separation between the two taxa (La Rosa et al., 2003a). Detailed information on the genetic relationship between T. nativa and Trichinella T6 is reported in Section 5. As with T. nati$v a$, Trichinella T6 larvae can survive in the frozen muscles of carnivores for long periods of time (Dick and Pozio, 2001). An outbreak of trichinellosis has been documented from the consumption of cougar meat infected with Trichinella T6 (Dworkin et al., 1996).

\subsubsection{Trichinella britovi Pozio et al., 1992 and the genotype Trichinella} T8 Pozio et al., 1992

Within the encapsulated clade, $T$. britovi is the species characterised by a wide geographical distribution covering the entire European continent (excluding some islands and the far north), north western Africa up to Guinea and south western Asia (Kazakhstan, Turkey, Israel, Syria, Iran, Afghanistan) (Fig. 2B) 

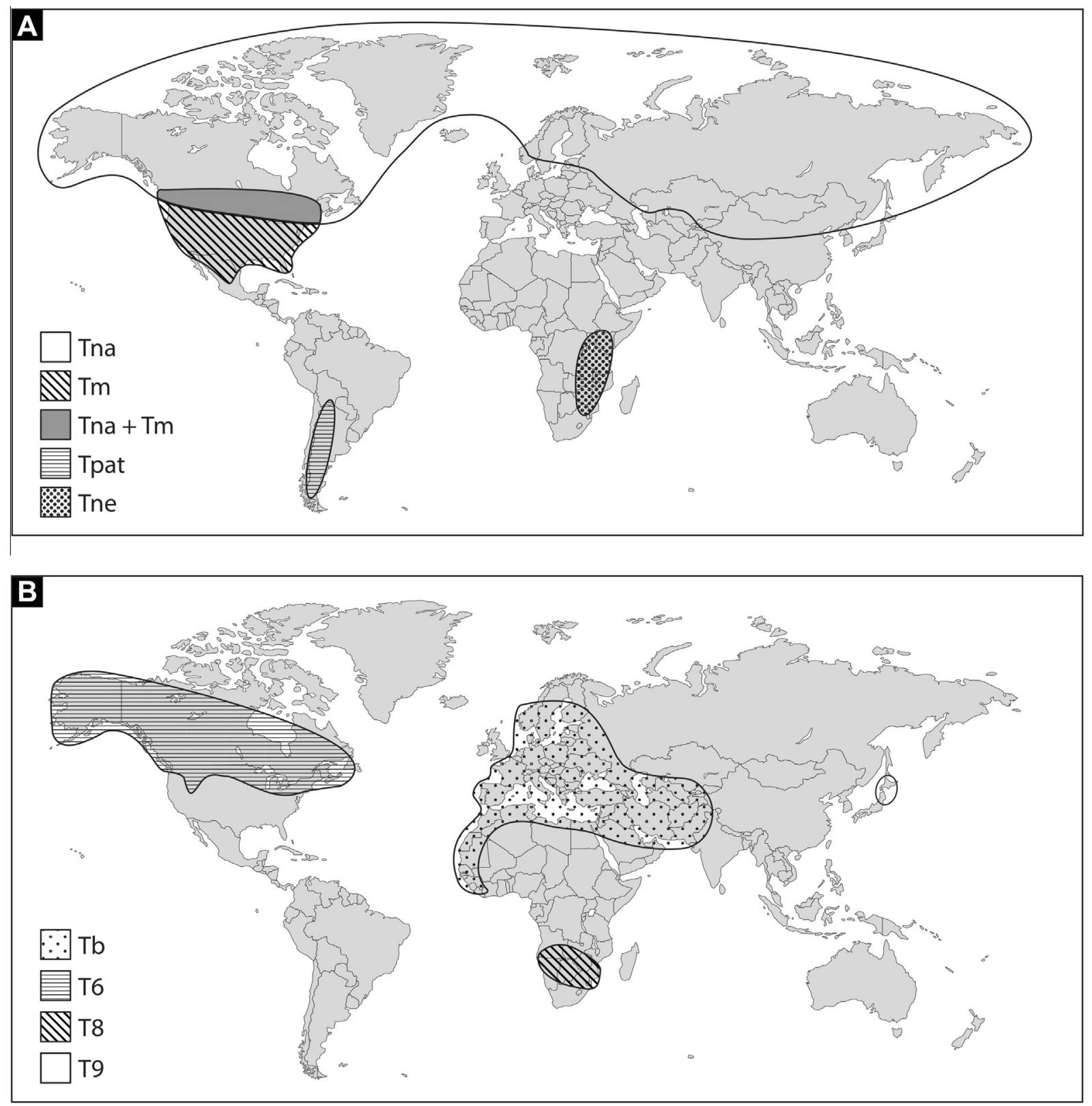

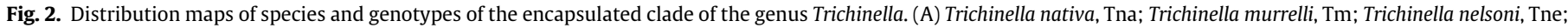
and Trichinella patagoniensis, Tpat. (B) Trichinella britovi, Tb; Trichinella T6, T8 and T9.

(Pozio et al., 2005a). No information is available for the Arabian Peninsula, Pakistan and India.

The preferential hosts of $T$. britovi are carnivorous mammals, but a prevalence ranging from $0.01 \%$ up to $3 \%$ has been detected among wild boars in Europe. The highest prevalence has been observed in wild boars in the northern European regions and the lowest in the southern regions of the continent. The difference in geographical prevalence could be the result of high humidity and warm temperatures which favour the survival of larvae in the muscles of dead animals, or of hunters who field-dress the carcasses and leave the entrails which enhance transmission to new hosts. Using the same infecting dose, experimental infections demonstrate that by 2 months p.i. the number of $T$. britovi larvae in swine muscles ranges from 1.6 to 280 times lower than that of $T$. spiralis. This is dependent upon the infecting dose, the muscle tissue examined and the breed of the infected pigs (Nöckler et al., 2005). A consistent number of trichinellosis cases in Europe are caused by $T$. britovi; in addition, $T$. britovi was the sole etiological agent of trich- inellosis in Algeria, Senegal, Turkey, Israel, Syria, Lebanon and Iran (Pozio and Murrell, 2006; Akkoc et al., 2009; Mowlavi et al., 2009).

The genotype Trichinella T8 is related to T. britovi as demonstrated by successful interbreeding under experimental conditions (Pozio et al., 2009a). Trichinella T8 has been detected in sylvatic carnivores (lions, spotted hyenas and a leopard) in South Africa and Namibia (Fig. 2B) (ITRC; Marucci et al., 2009; Mukaratirwa et al., 2013). A mixed infection of Trichinella T8 and T. nelsoni was detected in a lion and in a leopard from the Kruger National Park of South Africa (ITRC; Marucci et al., 2009). This parasite has never been reported as a cause of trichinellosis; however, its limited distribution and its genetic similarity to $T$. britovi render it difficult to differentiate the two in standard epidemiological studies.

\subsubsection{Trichinella murrelli Pozio and La Rosa, 2000 and the genotype} Trichinella T9 Nagano et al., 1999

This species has been detected most often in carnivorous mammals (black bears, raccoons, bobcats, cougars, red foxes, coyotes 
Table 1

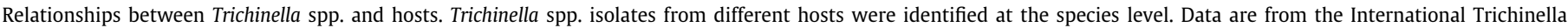
Reference Center (ITRC, http://www.iss.it/site/Trichinella/scripts) and from the literature ${ }^{\mathrm{a}}$.

\begin{tabular}{|c|c|c|c|c|c|c|c|c|c|}
\hline Trichinella spp. & Human & Suidae family & Muridae family & 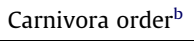 & Equidae family & Other mammalian families & Birds $^{c}$ & Reptiles $^{\mathrm{d}}$ & Total \\
\hline \multicolumn{10}{|l|}{ Encapsulated clade } \\
\hline T. spiralis & 11 & 1,989 & 49 & 227 & 12 & $11^{\mathrm{h}}$ & 0 & 0 & 2,299 \\
\hline T. nativa $\mathrm{e}^{\mathrm{e}}$ & 2 & 10 & 1 & 615 & 0 & 0 & 0 & 0 & 628 \\
\hline T. britovi ${ }^{\mathrm{f}}$ & 6 & 1,025 & 9 & 1,827 & 2 & $1^{\mathrm{i}}$ & 0 & 0 & 2,870 \\
\hline T. murrelli ${ }^{\mathrm{g}}$ & 1 & 0 & 0 & 80 & 1 & 0 & 0 & 0 & 82 \\
\hline T. nelsoni & 0 & 1 & 0 & 16 & 0 & 0 & 0 & 0 & 17 \\
\hline T. patagoniensis & 0 & 0 & 0 & 3 & 0 & 0 & 0 & 0 & 3 \\
\hline \multicolumn{10}{|c|}{ Non-encapsulated clade } \\
\hline T. pseudospiralis & 1 & 34 & 4 & 17 & 0 & $1^{\mathrm{j}}$ & 6 & 0 & 63 \\
\hline T. papuae & 4 & 8 & 0 & 0 & 0 & 0 & 0 & 11 & 23 \\
\hline T. zimbabwensis & 0 & 0 & 0 & 1 & 0 & 0 & 0 & 17 & 18 \\
\hline Total & 25 & 3,067 & 63 & 2,786 & 15 & 13 & 6 & 28 & 6,003 \\
\hline
\end{tabular}

a ITRC (4,406 isolates); Beck et al., 2009a (21 isolates); Beck et al., 2009b (one isolate); Blaga et al., 2009 (40 isolates); Burke et al., 2008 (17 isolates); Cuttel et al., 2012 (one

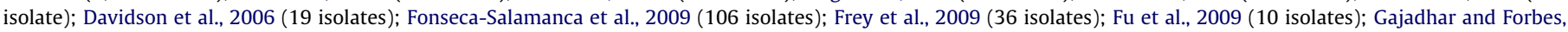

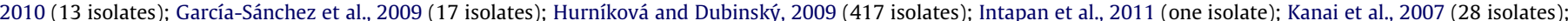

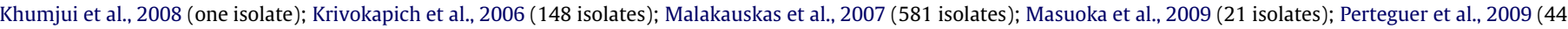
isolates); Ribicich et al., 2010 (three isolates); Shaikenov and Boev, 1983 (63 isolates); Wang et al., 2012b (nine isolates).

b Canidae, Felidae, Herpestidae, Hyaenidae, Mustelidae, Procyonidae, Ursidae and Viverridae families.

c Accipitridae, Catharitidae, Corvidae and Strigidae families.

d Crocodilidae and Varanidae families.

e Including Trichinella T6.

${ }^{f}$ Including Trichinella T8.

g Including Trichinella T9.

h Armadillos (Dasypodidae family) and opossum (Didelphidae family).

i European beaver (Castoridae family).

j Tiger quoll (Dasyuridae family).

and a domestic dog) in the United States and in some areas of southern Canada (Pozio and Murrell, 2006; Gajadhar and Forbes, 2010; Reichard et al., 2011) (Fig. 2A). Since T. murrelli has been detected in California, New Mexico and Texas, it may also circulate among carnivores in Mexico. To date, there has been only one report of T. murrelli in a non-carnivore. This infection was found in a horse exported from Connecticut, USA to France in 1985 which resulted in an outbreak of trichinellosis in humans (Ancelle, 1998). A second outbreak of trichinellosis caused by T. murrelli has recently been documented in relation to the consumption of raw meat from a black bear hunted in northern California (Hall et al., 2012).

Trichinella T9 has been detected in sylvatic carnivores of Japan (black bears, red foxes, raccoon dogs) (Fig. 2B) (Kanai et al., 2007) and had been considered related to T. britovi with which it interbreeds under experimental conditions (Nagano et al., 1999). However, a multi-gene study of Trichinella phylogeny indicated that Trichinella T9 was more closely related to T. murrelli than to T. britovi (Zarlenga et al., 2006). This finding was corroborated by an examination of ITS2 sequences (Pozio et al., 2009a) and further supported in a recent study evaluating the classification of T. patagoniensis (Krivokapich et al., 2012). Trichinella T9 has not yet been reported as a cause of human infections for reasons similar to those expressed for Trichinella T8.

\subsubsection{Trichinella nelsoni (Britov and Boev, 1972) sensu stricto (Pozio et al., 1992)}

There is little information on this species. Trichinella nelsoni circulates predominantly in wild animals (mainly scavenger carnivores such as lion, spotted hyena, striped hyena, bat eared fox, cheetah and serval) from Kenya to South Africa (Fig. 2A). Double infections of $T$. nelsoni and Trichinella T8 have been detected in a lion and in a leopard from the Kruger National Park of South Africa (Marucci et al., 2009). The precise relationship between T. nelsoni and wildlife confines the circulation of this parasite to environmentally-protected areas (Pozio et al., 1997b; Marucci et al., 2009; La Grange et al., 2009, 2010, 2013). There are a few reports on human trichinellosis from the consumption of pork from warthogs and bush pigs in Kenya and Tanzania for which the etiological agent could have been T. nelsoni (Pozio, 2007); however, this has never been verified.

\subsubsection{Trichinella patagoniensis Krivokapich et al., 2012}

This is the most recently described taxon of the genus Trichinella. It was discovered in the muscles of a cougar (Puma concolor) from Argentina in 2004 (Krivokapich et al., 2008). Thereafter, this parasite was isolated from two additional cougars in Argentina and subsequently described as a new species (Fig. 2A) (Krivokapich et al., 2012). Single male and female adults of $T$. patagoniensis cross only with single female and male adults of $T$. britovi and $T$. murrelli in both directions, but they produce infertile F1 offspring. Natural and experimental infections show that $T$. patagoniensis is better adapted to carnivores (e.g. cougars and cats) than rodents (e.g. mice, rats), and it shows a very low reproductive capacity index in pigs (Krivokapich et al., 2012). Surprisingly, muscle larvae of $T$. patagoniensis are somewhat resistant to freezing in cat muscle tissue kept at $-5^{\circ} \mathrm{C}$ for 3 months, but do not survive in cat muscles frozen at $-18{ }^{\circ} \mathrm{C}$ for 1 week. This suggests a greater similarity to T. murrelli than to T. britovi. Larvae of T. patagoniensis can be distinguished from larvae of the other Trichinella taxa by the length of IsrRNA expansion segment V (ESV) which is $161 \mathrm{bp}$. Phylogenetic relationships of T. patagoniensis are discussed in Section 3.2. No human infections caused by T. patagoniensis have been described to date.

\subsection{The non-encapsulated clade}

\subsubsection{Trichinella pseudospiralis Garkavi, 1972}

This is the only non-encapsulated species capable of infecting both mammals and birds. Trichinella pseudospiralis larvae do not induce collagen capsule formation in the nurse cell. For this reason, it is extremely difficult to detect $T$. pseudospiralis larvae in the host muscles using a trichinoscope. After its isolation in 1972, reports of this species in different animal hosts (mainly 
mammals) began to increase. However, this sudden rise occurred when the artificial digestion method replaced the traditional trichinoscopy to detect Trichinella larvae in muscle tissues. As of this report, T. pseudospiralis has been identified in 63 isolates most of which were collected from wild boars (Table 1). Three populations of $T$. pseudospiralis can be distinguished by the region within the lsrDNA ESV (Zarlenga et al., 1996). These genotypes were further defined as Palearctic, Nearctic and Australian populations (La Rosa et al., 2001).

The cosmopolitan distribution of this species and its infectivity for birds corroborates the hypothesis that birds have played an important role in the dispersion of this parasite species (Fig. 1B). However, the number of reports of $T$. pseudospiralis in naturallyinfected birds is extremely limited due to the low number of susceptible birds which have been tested for Trichinella. Indeed, $T$. pseudospiralis has been detected in only seven naturally-infected carnivorous birds to date (Pozio, 2005). As such, it follows that $T$. pseudospiralis has been documented more frequently in mammals than in birds (Table 1 ).

One human infection, probably acquired in Tasmania (Australia), and three additional outbreaks involving a total of 92 people, in Kamchatka (Russia), Thailand and France have been reported (Andrews et al., 1995; Britov, 1997; Jongwutiwes et al., 1998; Ranque et al., 2000). The Trichinella larvae isolated from a muscle biopsy of a patient from the Thai outbreak of 1995 were identified as T. pseudospiralis by random amplified polymorphic DNA (RAPD) (Jongwutiwes et al., 1998). Today, we know that another non-encapsulated species, $T$. papuae, which had not been described in 1995, is circulating in Thailand. As such, we cannot exclude the possibility that the low resolution of RAPD analysis was related to an infection derived from the biologically distinct, but genetically similar T. papuae and not to an infection caused by $T$. pseudospiralis.

\subsubsection{Trichinella papuae Pozio et al., 1999a}

The circulation of Trichinella parasites in swine from New Guinea was first reported by Madsen in 1964 and initially thought to be T. spiralis (Anonymous, 1964). Non-encapsulated larvae of Trichinella were re-discovered in 1988 in the muscles of domestic sows and wild pigs in south-west Papua New Guinea (PNG) (Owen et al., 2000). The combination of molecular and biological data permitted the classification of these parasites as a new species (Pozio et al., 1999a). Using molecular techniques to examine larvae obtained from muscle biopsies of people who consumed pork from wild pigs hunted in Thailand and Malaysia (Khumjui et al., 2008; Kusolsuk et al., 2010; Intapan et al., 2011), T. papuae was identified as the causative agent (Fig. 1B). In like manner, larvae from a wild pig from Gabba (Gerbar) Island in the Torres Strait between PNG and the Cape York Peninsula of Australia (Cuttell et al., 2012) were also classified as T. papuae. In a surprising twist of events, $T$. papuae had been detected in farmed saltwater crocodiles in PNG which were fed infected pork scraps (Pozio et al., 2005b). Trichinella papuae infection was also suspected in eight people who had consumed raw meat from a soft-shelled turtle (Pelodiscus sinensis) purchased in a Taiwanese restaurant (Lo et al., 2009) demonstrating further the potential of $T$. papuae to infect poikilothermic hosts in addition to domestic and wild pigs. Although there is a dearth of geographicallydistinct isolates of $T$. papuae, we nonetheless suspect that the distribution area of this species encompasses Australasia and south eastern Asia, and overlaps with the distribution area of the saltwater crocodiles which could have played an important role as a reservoir and 'vector' of $T$. papuae in the myriad of islands present in this region (Fig. 1B).

\subsubsection{Trichinella zimbabwensis Pozio et al., 2002}

This species, first detected in farmed Nile crocodiles in 1995, together with $T$. papuae are the only endo-parasites which are able to complete their entire life-cycles in both homeothermic and poikilothermic hosts. This seems to indicate that these two Trichinella spp. are capable of activating different physiological mechanisms according to the specific vertebrate class. Trichinella zimbabwensis has been detected in farmed Nile crocodiles in Zimbabwe and Ethiopia and in wild crocodiles in Zimbabwe, Mozambique and South Africa (Fig. 1B) (Pozio et al., 2002, 2007; La Grange et al., 2009, 2013). It has also been found in Nile monitors in Zimbabwe (Pozio et al., 2007; http://www.iss.it/site/Trichinella/scripts/) and in a lion in South Africa which is the only mammal infected with T. zimbabwensis detected in nature to date (La Grange et al., 2010). Experimental infections have shown a broad spectrum of susceptible homeothermic and poikilothermic hosts ranging from laboratory mice and rats, pigs, foxes, primates, caimans and savannah monitors to Burmese pythons and the African helmeted turtles, albeit to a lesser degree (Mukaratirwa and Foggin, 1999; Pozio et al., 2002, 2004; Hurníková et al., 2004; Mukaratirwa et al., 2008). Trichinella zimbabwensis has not yet been documented in humans. However, experimental infections in vervet monkeys and baboons resulted in severe clinical signs noted by high fever, diarrhoea, periorbital edema and muscular pains which are consistent with being a viable human pathogen (Mukaratirwa et al., 2008). The distribution of this species is still unknown, but we can speculate that $T$. zimbabwensis is present throughout sub-saharan Africa.

\section{Phylogeny}

\subsection{The first studies}

Except for the delineation between encapsulated and nonencapsulated groups and the smaller size of $T$. pseudospiralis relative to other species, parasites of the genus Trichinella are morphologically indistinguishable (Dick, 1983; Lichtenfels et al., 1983; Pozio et al., 1992). As such, the phylogeny of this genus remained in flux for years following the initial reports of its discovery in 1835. In the late 1980s, more in-depth studies of the taxonomy and phylogeny of this genus were begun but these relied heavily on biological markers. However, overlap in defining markers among the various species and genotypes prompted the search for genetic and biochemical characters to better elucidate members of the genus.

Initially, analyses of biochemical data were performed using distance algorithms (UPGMA) that rely on sequence similarities resulting from shared ancestral characters rather than shared derived characters. Among the first comprehensive dendrograms were those based upon allozyme data (La Rosa et al., 1992) where eight distinct gene pools were identified among members of the genus. Similar findings were generated by Bandi et al. (1995) using RAPDs and allozymes. However, problems with the use of RAPDs (see Campbell et al., 1994; Pozio et al., 1999b), together with the requirement for extensive controls, dictated that alternative approaches to phylogenetic analysis were required. In 1998, Zarlenga (1998) used preliminary mitochondrial DNA (mtDNA) sequence data to produce a UPGMA tree that showed strong support for the topology produced by Bandi et al. (1995), although variations were observed in the placement of the Palearctic and Nearctic sylvatic genotypes.

In 2003, multilocus enzyme electrophoresis data was used to examine Trichinella phylogeny using neighbour-joining (NJ) methods (La Rosa et al., 2003b). Although NJ is a distance-based algorithm, unlike UPGMA, it does not assume all lineages evolve at the same rate. However, it can at times assign negative lengths 
to some of the branches. The trees were among the first to segregate T. pseudospiralis, T. papuae and T. zimbabwensis within the non-encapsulated clade. Also, T. nelsoni was proposed as the ancestral encapsulated genotype. This did not agree with other distancebased topologies that had been previously generated. Furthermore, these data suggested that the Arctic genotypes, T. nativa and Trichinella $\mathrm{T} 6$, had not diverged recently. This was perplexing given that gene-flow has been observed in multiple instances among these sympatric genotypes (La Rosa et al., 2003a; Dunams-Morel et al., 2012) and biological characters supported a more recent evolutionary trajectory. Overall discrepancies in tree topologies may have resulted from deficiencies embodied in isoenzyme analyses. Unlike specific sequence data, protein banding patterns result from an average change in amino acid content over the length of the peptide. Thus, isoenzyme data are very good for identifying groups or changes within a taxon but are not as robust in gauging the magnitude of the changes or in clarifying the branching process. For this reason, studies began to shift more toward DNA sequencing to support or refute the biologically- and biochemically-informed phylogenies.

Maximum likelihood (ML), parsimony and/or NJ methods were subsequently used to study Trichinella phylogeny focusing on the D3 domain of the nuclear ribosomal DNA (Gasser et al., 2004). Strong bootstrap support was observed for monophyly between $T$. spiralis and T. nelsoni, and between T. nativa and Trichinella T6. Once again, non-encapsulated species that frequent poikilothermic vertebrate hosts, i.e. T. papuae and T. zimbabwensis, clustered independently of those found predominantly among homeothermic animals i.e. T. pseudospiralis, and the relative divergence times of those species found in the Holarctic exhibiting the freeze-resistant characteristic became more clear (Gasser et al., 2004). However, the placement of $T$. spiralis and $T$. nelsoni remained unresolved as did a number of the sylvatic genotypes and species.

\subsection{A milestone for Trichinella phylogeny}

In 2006, Zarlenga et al. (2006) examined the phylogenetic relationships among all extant species and well-delineated genotypes excluding $T$. patagoniensis which has only recently been discovered (Krivokapich et al., 2008) and classified (Krivokapich et al., 2012). Unlike previous work, this study examined three distinct sequences: the nuclear second internal transcribed spacer, the mitochondrial lsrDNA and the cytochrome oxidase I DNA. Maximum likelihood-based analysis and Bayesian phylogenetic inference were used to model character evolution. Such an approach is more powerful than distance methods or non-parametric statistical methods such as parsimony. This study supported prior knowledge and solidified the classification of $T$. spiralis as the ancestral species among the encapsulated clade (Fig. 3). It further concluded that the arctic species and genotypes were indeed the most recently diverged. This study proposed a scheme for the origins and radiation of the genus in which contemporary species of Trichinella and the divergence of the primary subclades occurred in Eurasia, possibly during the late Tertiary (from 65 million to 2.6 million years ago), and diversification of extant species was estimated to have occurred only within the last 20 million years (MYBP, million years before present). Based upon biogeographical information and our knowledge of host associations, it is now believed that mammalian carnivores translocated encapsulated forms to Africa during the late Miocene and Pliocene, and across the Bering Land Bridge to the Nearctic thereafter when crown species diversified (Fig. 4) (Zarlenga et al., 2006).

Recently, a new species of Trichinella, T. patagoniensis, was identified and characterised as endemic to South America (Krivokapich et al., 2012). First reports of this genotype surfaced from Krivokapich et al. (2008) who also used a multi-gene approach for phylogenetic inference but chose not to concatenate the sequences and evaluated the data independently. Two trees were produced and although they varied somewhat, they were in general agreement with Zarlenga et al. (2006). In addition, the data placed T. patagoniensis closer to the base of the encapsulated clade but its exact position could not be resolved when nuclear and mtDNA data were compared. Additional genetic analyses (Krivokapich et al., 2012) using isolates of this new species supported its independent evolution and resulted in a monophyletic clade with T. nelsoni. However, the analysis did not provide additional clarification to the location of $T$. patagoniensis within the whole of the encapsulated clade (Fig. 3).

Inasmuch as Trichinella is a member of the Dorylaimia, a lineage that emerged early in the evolution of the phylum Nematoda (Blaxter et al., 1998; Holterman et al., 2006; Meldal et al., 2007), a deep history for initial divergence of this lineage is supported (Zarlenga et al., 2006). This is in stark contrast to the emergence of extant species which share extensive morphological and biological characters, and to information that dates the appearance of contemporary encapsulated species to within 15-20 MYBP. The absence of fossil records places substantial importance on understanding host-parasite assemblages to help decipher: (i) the geographic origins of this genus, (ii) faunal expansion throughout the continents, and (iii) the ability of Trichinella spp. to adapt to diversified host species (Pozio et al., 2009a). Inasmuch as contemporary predatory guilds of hosts are thought to have originated in the Palearctic and continue to play a role in the distribution of $T$. spiralis, it is likely as well that this region constituted a focal point for the origins of encapsulated extant species. This is supported by the relatively high genetic variation among $T$. spiralis isolates obtained from Eurasia (Rosenthal et al., 2008) and agreement that $T$. spiralis is ancestral among the encapsulated genotypes. This would have been followed by expansion into western Europe then across Beringia and into North America <2 MYBP where T. spiralis isolates characterised from these regions have been reported as genetically uniform (Rosenthal et al., 2008) (Fig. 4). However, fossil remains of extinct carnivores in southern Africa and South America, presumably occurring prior to the spatial separation of Africa and South America, in conjunction with the exclusive presence of T. nelsoni in Africa and T. patagoniensis in South America, support a tree in which either $T$. nelsoni or $T$. patagoniensis could be the ancestral encapsulated species (Fig. 4). Timing of the final separation of South America from Africa to 92 MYBP in conjunction with the predicted age of the encapsulated clade (20 MYBP) argues that the appearance of $T$. patagoniensis in South America is more likely due to the expansion of Eurasian felids into Neotropical regions within the past 8-10 million years followed by some level of extinction in the Nearctic (Pozio et al., 2009a). Key to understanding this dilemma is obtaining new data on Trichinella genotypes derived from poorly sampled regions of the world, preferably in the southern hemisphere, as well as new data that can inform us on the evolution of Trichinella during the vast period spanning the divergence of the Trichuridae and Trichinellidae from a common ancestor (approximately 250-300 MYBP), to the appearance of extant encapsulated species.

\section{Trichinella "omics"}

\subsection{Transcriptomics}

The tree of life has three primary branches: Bacteria, Archaea and Eukaryotes. Understanding this tree has been a major focus of the genome sequencing era. To better help comprehend how diverse organisms are related and how evolution has played a role in their development, the National Human Genome Research 


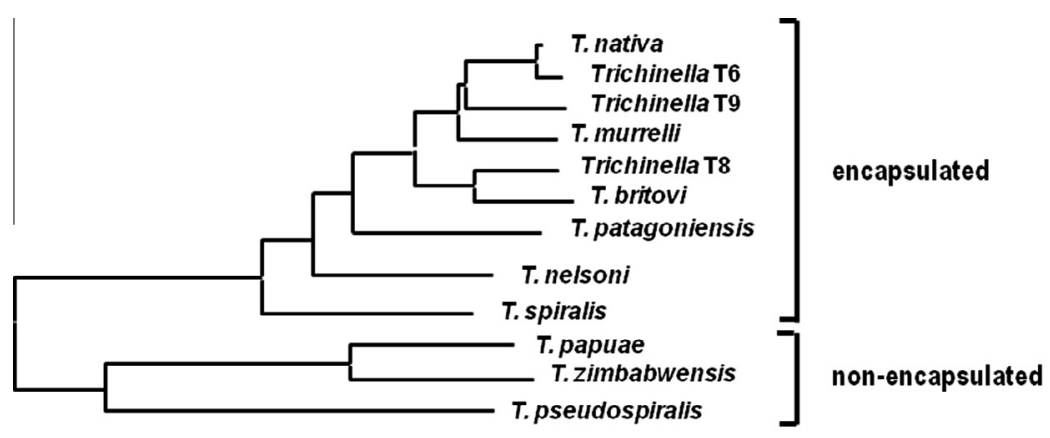

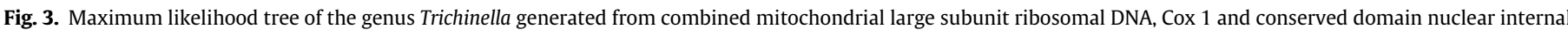

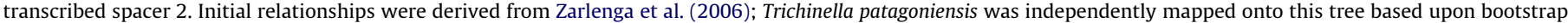
values for 5S intergenic spacer region sequences from Krivokapich et al. (2008). Primary separation of encapsulated and non-encapsulated taxa is supported.

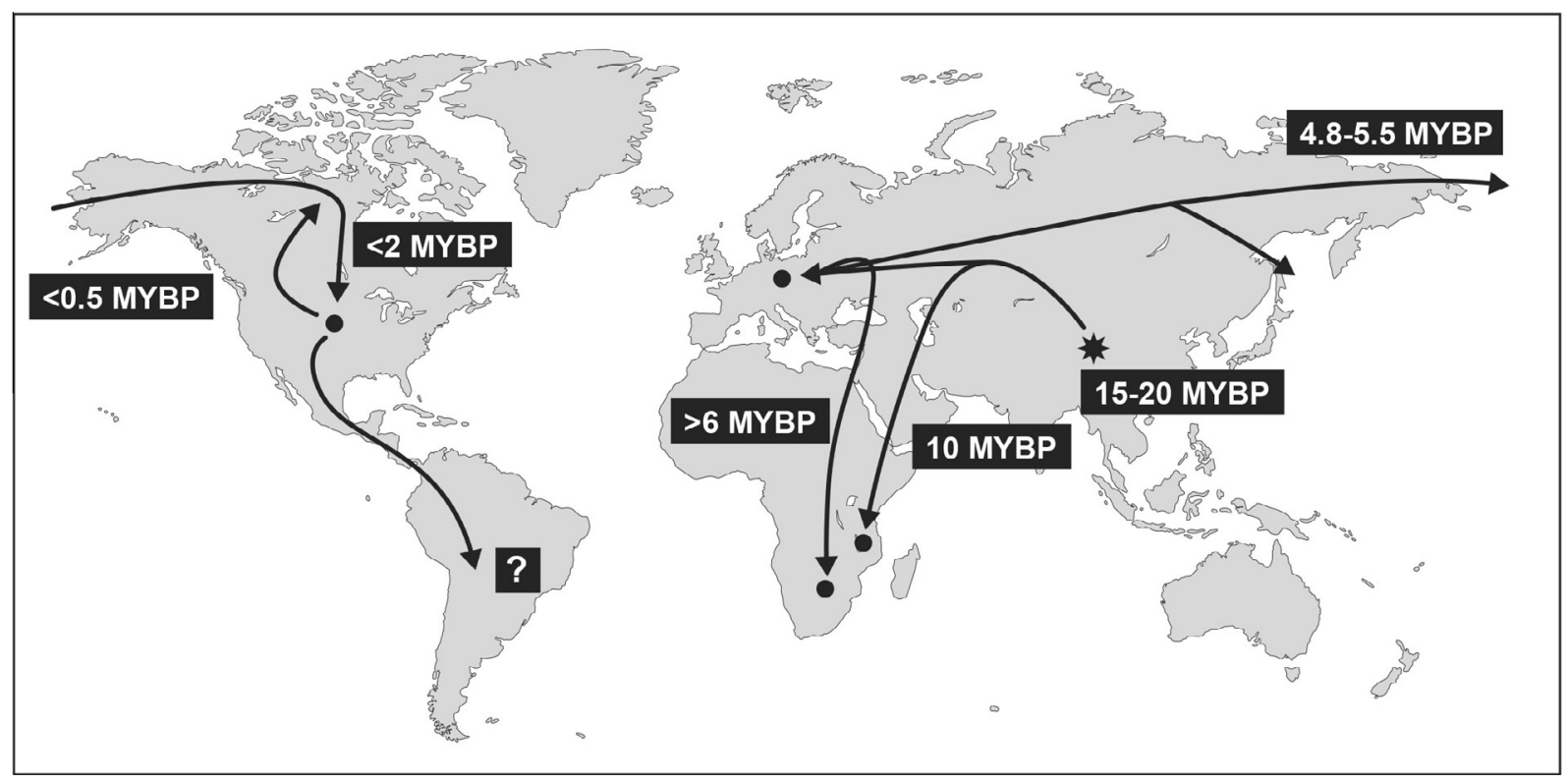

Fig. 4. Projected worldwide dissemination and timeline of extant Trichinella spp. and genotypes. Modified from Zarlenga et al. (2006).

Institute (http://www.genome.gov/) decided nearly 10 years ago to sequence the genomes of distinct and very diverse eukaryotes ranging from the gigantic to the microscopic. Within the group selected were the savannah elephant, domestic cat, armadillo, kangaroo, cow and a host of smaller organisms encompassing molds, snails and worms. The more distinct eukaryotes such as the slime mold and the single-celled swimmer were chosen to provide needed information on genome organisation. Key to this study was the selection of an appropriate nematode genome, to wit, $T$. spiralis. The suitability of choosing the genus Trichinella was founded in the following: (i) it is among the select few nematode parasites that diverged very early in the evolution of the phylum and is a member of a clade that is poorly represented in the DNA sequencing pool; (ii) it is unique in that it requires only a single host to complete its life cycle; (iii) it is a member of a genus that exhibits unlimited host range; (iv) it can be maintained in laboratory animals and thereby provide pure DNA; and (v) Trichinella spp. remain a zoonotic concern worldwide.

The first efforts toward unravelling the genetics of Trichinella involved studies of the transcriptomes of the three key life cycle stages; the immature L1 (newborn larvae; NBL), mature L1 (muscle larvae; ML) and adult worms (Ad) (Mitreva et al., 2004, 2005). Using expressed sequence tags (ESTs), the authors identified $>3,200$ genes among which were a collection of sequences that support the ancient divergence of the genus and Trichocephalidaspecific sequences that may have been important in the evolution of this group of organisms. A number of the identified sequences were stage-specific and a disproportionately large portion consisted of isoforms of proteins classically associated with immunodominant secretory products of the ML i.e., DNAse II-like. Clear evidence of a hierarchical relationship to Caenorhabditis elegans was exhibited in the identification of over 450 matches with $C$. elegans homologues with RNA interference phenotypes, presumably sequences related to sustaining basic biological functions.

Other transcriptome studies also surfaced using next-generation sequencing and focusing on gene regulation under the control of small regulatory elements in Trichinella (Liu et al., 2011) and genes associated with the host-parasite interface (Liu et al., 2012). As observed in most metazoan transcriptomes studied to date, $T$. spiralis was shown to possess micro RNAs and endo-small interfering RNAs that exhibited stage-specific expression profiles. Among these, 213 sequences were deemed to be Trichinellaspecific whereas only 21 were conserved among the metazoan transcriptomes studied to date (Liu et al., 2011). Among the 9,000 genes ( $65 \%$ of the predicted transcriptome) identified by Liu et al. (2012) using pyro-sequencing, many were stage-specific and a subset were proposed as associated with parasite invasion and/or immune modulation. 


\subsection{Genomics}

Early reports of genome sequencing efforts for $T$. spiralis began to surface as early as 2008 (Mitreva and Jasmer, 2008, 2010; Zarlenga et al., 2009). Excitement peaked over the availability of data from a nematode that diverged very early in the evolution of the phylum. The data not only advanced evolutionary studies, but research began comparing genomes from widely diverse lineages in the hope of identifying pan-specific sequences that may reflect new drug targets for control of nematodes as well as genes linked to controlling the host immune response.

In 2011, the first draft of the $T$. spiralis genome was published (Mitreva et al., 2011). A number of interesting findings surfaced from this work. First, the $T$. spiralis genome is $64 \mathrm{Mb}$ in length. While this agreed well with size estimates from flow cytometry ( $1 \mathrm{C}=71 \mathrm{Mb}$ ), it was nonetheless far smaller than what had been initially predicted, and smaller than the prototypical nematode, C. elegans ( $100 \mathrm{Mb})$. Second, comparing the Trichinella genome to others that were available at the time, it was determined that intrachromosomal rearrangements were relatively common throughout the phylum. However, there appeared to be a disproportionate number of protein family deaths over births in parasitic versus non-parasitic nematodes. It has been postulated that this arose from the confined, more predictable niche of parasitic nematodes relative to the unpredictable nature of a free-living environment (Wang et al., 2012a). Third, when comparing the nematodes as a group to a member of their next closest relative, the arthropods i.e. Drosophila melanogaster, there was a high level of gene loss and gene gain within each nematode species, suggesting that events such as these may have figured prominently in the evolution of the Nematoda. Finally, the data corroborated that T. spiralis, a member of a parasite group that emerged early in the evolution of the phylum, shared as much similarity with $C$. elegans, a nematode from a crown clade, as it did with a member of the arthropods, D. melanogaster. This offered further support to the belief that key similarities among these disparate organisms was likely partitioned into those genes linked to sustaining basic life functions.

This Trichinella sequence information was used in a broader analysis of how metazoan proteomes changed over the course of evolution in an effort to help clarify processes that drive species diversity and adaptation (Wang et al., 2012b). Again, the Trichinella data were critical in that the lineage from which it was derived was substantially different from the other nematodes used in the analysis. The study examined the appearance and disappearance, and the duplication and deletion, of protein families and the domains that constitute proteins. Proteome data from vertebrates, arthropods and nematodes were compared. Results suggested that the higher number of new families in free-living nematodes coincides with their remarkable ability to successfully adapt to very diversified environments (Andrassy, 1976). In order to do this, they require a larger pool of proteins to help deal with less controlled forces associated with living freely. Results also showed that the shuffling of domains between proteins was much more influential in the evolution of proteins in nematodes and arthropods than in vertebrates.

It is clear that the era of genome sequencing is well entrenched in the understanding of evolution. As the number of genomes increases, more clarity will befall current hypotheses. Preliminary sequence data has been generated on the non-encapsulated species, T. pseudospiralis (Zarlenga et al., 2009) and work has also begun on the crown species, T. nativa (Zarlenga, unpublished data).

\subsection{Proteomics}

Coincident with the Trichinella transcriptome and genome studies were those that embraced the proteome. Among the first attempts looking directly at the proteomes of Trichinella spp. was work conducted by Robinson and Connolly (2005) and Robinson et al. (2007) who studied the excretory-secretory (ES) products of $T$. spiralis. The importance of targeting this subset of proteins was understanding how the parasite controls its local environment during the parenteral phase of development. Using MALDI-TOF-mass spectrometry (MS) and tandem MS, these authors examined a small subset of proteins (52); among them, the majority (43) were secreted glycoproteins. They later advanced this work with comparative analyses of ES proteins between very distinct species of the genus, $T$. spiralis and T. pseudospiralis. Not surprisingly, key immunodominant and secreted antigens dominated the protein profiles.

Dea-Ayuela and Bolás-Fernández (2005) used similar technology but focused on a subset of proteins that were within crude worm extracts of $T$. britovi and Trichinella T8 and also immunoreactive. Among this subset, they separately examined those that were immunologically cross-reactive and those that were species-specific in the hope of targeting proteins that differentiate the infection process among these genotypes. Most recently, Wang et al. (2012c) used proteomics to study changes in proteins from adult parasites as they traverse the intestines. The goal was to identify "invasion-related" proteins that coincided with the parasite entering the intestinal epithelium. The study involved looking at changes in both HCT-8 cells incubated in the presence of T. spiralis as well as changes in the parasite proteome. Results showed that the cells responded with elevated expression in several key proteins that, uncharacteristically, were also immunologically reactive with serum from $T$. spiralis-infected mice. Changes in T. spiralis proteins were also observed; in particular, 69 proteins were deemed demonstrably different while in the presence of HCT-8 cells, 54 of which could be annotated. However, research linking changes in protein levels to the infection process are still needed.

\section{Population genetics and microsatellites}

Some years ago, research conducted on gastrointestinal (GI) nematodes of cattle demonstrated high levels of genetic diversity both between and within worm populations (Dame et al., 1993). Further, this work showed that the total genetic divergence between any two geographical populations of GI nematodes (Ostertagia ostertagi), was partitioned within any single population of worms; indeed, even within a single animal. Analysing withinpopulation mtDNA diversity, the authors found five to 10 times greater genetic variability in $O$. ostertagi and other GI nematodes than reported in other taxa. Surprisingly, this level of genetic variation was not relegated to the mtDNA but has since been observed throughout the genomes of nematodes. Such a phenomenon can be equated to the ability of nematodes to readily adapt to change. This can be clearly seen today with the ability of parasites to become resistant to nearly every anthelmintic that has been thrust upon them to date. This level of genetic heterogeneity has posed difficulties performing population studies using more conventional methodologies such as microsatellites (MSATs). Trichinella spp. are somewhat different from other parasitic nematodes. They have the ability to generate "clonal populations" because their presence in nature is relatively rare so the probability of multiple infections in the same host is equally rare.

The first clear indication that MSATs could be used to investigate population variation within Trichinella was presented in 1996 by Zarlenga et al. (1996). In this work, the authors demonstrated that $T$. pseudospiralis exhibited substantial MSAT variability within the ESV of the lsrRNA. This variability was of ample magnitude and sufficiently conserved that three distinct variants were identified among the T. pseudospiralis isolates available. Furthermore, this variability was constrained where little within population variation was observed. Later, La Rosa et al. (2001) and more 
recently $\mathrm{Wu}$ et al. (2007) concluded that $T$. pseudospiralis from Australia, the Nearctic and the Palearctic were indeed distinct, using other biochemical markers.

In 2008, Rosenthal et al. (2008) advanced the application of MSATs to the study of Trichinella by identifying nine microsatellite loci and genotyping Trichinella spp. from 28 countries and four continents. They demonstrated that $T$. spiralis was quite uniform across Europe, North Africa and the Americas relative to other species and genotypes, but genetically diverse in Asia. From this, it was concluded that the origins of extant European lineages of $T$. spiralis probably coincided with the domestication of pigs and exhibited only recent incursion into North America as travel beyond western Europe increased.

A similar approach (MSATs and mtDNA sequencing) was used to investigate putative introgression among the freezing-resistant genotypes, T. nativa and Trichinella T6, in a region of the Canadian Arctic called Nunavut, the largest, northernmost and newest territory of Canada. In 2008, Reichard et al. (2008) used genomic DNAbased multiplex PCR (Zarlenga et al., 1999; Pozio and La Rosa, 2003) to identify a population of wolverines that harbored Trichinella T6 (91.7\%), T. nativa (2.8\%), or a mixture of the two genotypes (5.6\%). Dunams-Morel et al. (2012) later showed that many of these parasites exhibiting the Trichinella T6 genotype actually resembled T. nativa in their mtDNA. MSAT analyses corroborated that the nuclear genomes of most Nunavut isolates were indeed Trichinella $\mathrm{T} 6$ in nature but derive from the T. nativa matrilineage which suggests cross-hybridisation among these genotypes. These data show once again the utility and power of MSAT studies in evaluating Trichinella epidemiology and population genetics and provide some insight on gene flow within this genus.

The most recent example of MSATs in studying genetic divergence even within a highly homogeneous species i.e., T. spiralis, was demonstrated by La Rosa et al. (2012). In this study, a new bank of MSAT markers were developed to advance studies on individual larvae and examine both inter- and intra-species population variation among isolates. Twenty-two isolates each contributing 48 larvae were examined. In addition to validating the new MSAT markers, the study showed for the first time that $T$. spiralis in at least one host was derived from distinct parental lineages. This was likely the result of multiple, non-synchronous infections which had not yet been given the opportunity to interbreed. Nevertheless it demonstrated the power of the assay to discern intrapopulation variation.

\section{Relationship between Trichinella taxa and their host species}

In spite of the broad host range of these parasites, each species of Trichinella appears better adapted to some host species or families than others. The information displayed in Table 1 groups nearly all of the Trichinella isolates identified to date by the International Trichinella Reference Center (www.iss.it/site/Trichinella/ scripts) and the international literature. Most of this information originates from Europe; consequently, most of the identified isolates belong to one of the four species circulating on this continent. In swine, T. spiralis was detected 1.9 and 58.5 times more frequently than $T$. britovi and $T$. pseudospiralis, respectively. In carnivores, $T$. britovi was detected 8.0 and 107.4 times more frequently than $T$. spiralis and $T$. pseudospiralis, respectively. Other groups of species and genotypes infect carnivorous mammals exclusively (i.e., T. murrelli, T. patagoniensis, Trichinella T6, T8 and T9) or nearly so (i.e., T. nativa and T. nelsoni) (Zarlenga et al., 2006; Pozio et al., 2009b).

The adaptive strategies developed by Trichinella spp. seem to differ. For some Trichinella taxa, the humidity and the environmental temperatures of the habitat where the host lives coincide with the survival capability of the larvae in the host carcass and therefore its transmission to new hosts. In the Americas, the mountain lion (Puma concolor), which is widespread from the Arctic to Patagonia, can harbor T. nativa, Trichinella T6, T. murrelli or T. patagoniensis where the prevalence coincides with latitude. In Europe, wolves (Canis lupus), raccoon dogs and foxes (Vulpes vulpes) harbor T. nativa or $T$. britovi, infections of which also appear coincident with latitude. Leopards (Panthera pardus) and hyaenas (Hyaena hyaena) harbor T. nelsoni or T. britovi if they live in Africa or Asia, respectively. For other Trichinella taxa, the internal host niche i.e. adaptation, and the host immune system, seem to be more important than the habitat. For example, the preferential hosts of T. spiralis are swine and rodents, irrespective of the habitat. All the hosts of T. nativa, T. murrelli, T. patagoniensis, Trichinella T6, T8 and T9, are carnivores, whereas for T. britovi the hosts are carnivores (63\%) and swine (37\%). This predilection for carnivorous versus omnivorous hosts in more recently evolved genotypes appears to have been part of the evolutionary trajectory of the genus (Zarlenga et al., 2006; Pozio et al., 2009a). The raccoon dog is one example of how a single host species can be involved in the natural cycle of four parasite species belonging to the same genus. It was first introduced to the former Soviet Union from the Far East between 1928-1958 (Heptner and Naumov, 1998) and within a short period of time has become one of the most successful reservoir hosts for the four Trichinella spp. circulating in Europe (Pannwitz et al., 2010).

\section{Survival strategies of Trichinella spp. in nature}

Parasites of the genus Trichinella are transmitted among hosts by the ingestion of infected muscles, the typical predator-prey cycle. However, these nematodes have developed several mechanisms to increase their probabilities of being transmitted to new hosts by enhancing their survival in the host carcass when they are no longer protected by host homeothermy. Muscle larvae have an anaerobic metabolism which supports their survival in decaying muscles over long periods of time. This control is influenced by the environmental temperatures even though the tissue develops an angiogenesis process around the muscle cell-larva complex (Despommier, 1998). This survival is generally favoured by high environmental humidity and moderate temperatures. For example, infective larvae of the encapsulated species $T$. nativa and $T$. britovi were collected from the bottoms of conical vials where laboratory mouse carcasses had been stored at room temperature for 3 months and where only a few mouse bones remained. Infective Trichinella larvae were found within their collagen cysts engulfed by the greenish putrefaction liquid (Pozio, unpublished data). Presumably the capsule offered a level of projection and longevity to the parasites within the putrefying tissue. Even those species which do not generate collagen capsules, (T. pseudospiralis and $T$. papuae) are capable of surviving in decaying muscles albeit not as long; non-encapsulated species retained their infectivity up to 9 days at $20-24^{\circ} \mathrm{C}$, and up to 40 days at $5^{\circ} \mathrm{C}$ (Stewart et al., 1990; Webster et al., 2002; Owen and Reid, 2007).

Another biological mechanism developed by T. nativa larvae (and its related Trichinella T6 genotype), and to a lesser extent $T$. britovi larvae, is the ability to survive for extended periods of time in frozen muscles of carnivores. Trichinella nativa and T. britovi can survive for years and months, respectively, in frozen animal carcasses (Dick and Pozio, 2001). Yet amidst this freeze tolerance, genotypes found within the less temperate regions of the Holarctic are also capable of surviving putrefication and curing as found in igunaq consumed by the Inuit population of North America. These biological mechanisms have favoured animals with a scavenging behaviour (e.g., Hyaenidae, Canidae, Ursidae, Procyonidae, Corvidae, Crocodilidae, 
Varanidae) as important reservoir hosts of Trichinella nematodes. Other modes of transmission have been proposed and experimentally demonstrated such as the ingestion of faecal samples containing undigested muscle fibres harbouring Trichinella larvae, or Trichinella larvae which are transported outside the host by the faecal stream, but only when the 'donor' hosts were infected with huge numbers of larvae (Zimmerman et al., 1959; Schnurenberger et al., 1964). Although a scientific possibility, the importance of such transmission scenarios in nature is questionable.

Epidemiological investigations have shown that most animals naturally infected with Trichinella harbour low numbers of larvae ( $<10$ larvae/g in muscle predilection sites); very few animals harbour $>10$ larvae/g in comparable muscle tissues. Therefore, a new host will likely exhibit low worm burdens after ingesting flesh from a Trichinella sp.-infected wild animal. This observation is based on epidemiological data and is supported by the genetic structure of the Trichinella population present in a given host (i.e., a Trichinella isolate) (La Rosa et al., 2012). As a result, the transmission of low numbers of Trichinella worms will generally not induce sufficiently strong immune responses to preclude a second infection from taking place in the same host. However, it is possible that successful reinfection could result from immunosuppression of the host via other resident pathogens, starvation or environmental stress. A "mixture" and potential cross is then created in the ensuing unsuspecting host. While it is believed that valid species will not always interbreed and produce viable progeny, some genotypes capable of interbreeding in a laboratory setting have exhibited in nature the ability to produce hybrid progeny as well (Dunams-Morel et al., 2012).

Unlike humans, animals tend not to exhibit clinical signs of an infection even if they harbour hundreds of larvae per gram (LPG) of muscle. This suggests a long period of adaptation optimising the host-parasite relationship. In only a few cases, >1,000 LPG has been detected in naturally-infected animals. To date, the highest recorded infection exceeded 8,000 LPG in the diaphragm pillars of an asymptomatic pig in Romania (Gómez-Morales et al., 2012). For this reason, the term for the disease caused by Trichinella infection i.e., trichinellosis, should be used only when defining a human condition whereas 'Trichinella infection' should be applied when referencing animal infections.

\section{Human trichinellosis}

Evaluating the impact of zoonotic nematodes on humans is extremely important for assessing the overall risk to public health. In 1998, the global prevalence of trichinellosis was estimated at 11 million (Dupouy-Camet, 2000). This estimate was predicated on the assumption that the number of trichinellosis cases was similar to the number of people infected with Taenia solium (taeniasis/cysticercosis), because both pathogens are transmitted by consuming fresh or undercooked pork products. It should be noted, however, that there is a great disparity in the epidemiology and modes of transmission between these two parasites, and their overlap among populations of the world is coincidental at best. In 2007, a new estimate of the yearly incidence of trichinellosis suggested approximately 10,000 infections. This number was derived by aggregating the highest incidence rates reported in countries throughout the world over a 10 year period (Pozio, 2007). However, due to problems related to incomplete data from some geographical regions and the inconsistent quality of diagnostic criteria that define an infection, this was also deemed an insufficient estimate. As such, the World Health Organization's Foodborne Disease Burden Epidemiology Reference Group (FERG) requested a systematic assessment of the global incidence of trichinellosis. A thorough review of all available literature worldwide from 1986 to 2009 revealed 65,818 cases of trichinellosis and 42 deaths reported from 41 countries (Murrell and Pozio, 2011). Most of the infections (87\%) were documented in Europe and among these, as many as $50 \%$ had been reported in Romania. Although this was probably a more comprehensive estimate than what had transpired previously, this approach was constrained by its own set of drawbacks. First, the literature included only hospitalized persons in some countries, whereas all infected persons (both symptomatic and asymptomatic) were documented in other countries. Second, there was no standardisation in the diagnostic procedure. In many cases, non-validated serological tests were used to detect an infected individual. Third, as in past analyses it was anticipated that there was severe underreporting of infections due to cultural, economic or political reasons. Finally, the lack of medical knowledge and familiarity with trichinellosis by attending physicians where this disease is rare, in association with physiological symptoms which mimic flu-like conditions, probably contributed to a large number of misdiagnosed patients. In the first 70 years of the last century, the high number of human cadavers found infected with Trichinella larvae was in stark contrast to the low number of reported clinical cases. This suggests that the vast majority of human cases went undetected (Kim, 1983). As an example, from 2008 to 2010, new outbreaks of trichinellosis in humans were documented in remote areas of the Uttarakhand state (India) following the consumption of raw or undercooked wild boar meat. This resulted in high mortality (26.2\% of infected patients) due to late diagnoses and/or incorrect treatment (Sethi et al., 2010).

The most important factors contributing to the maintenance and spread of trichinellosis are the concomitant occurrence of Trichinella sp. infections in domestic animals and/or wildlife and its association with the consumption of raw or undercooked meat. Cultural preferences such as the preparation and consumption of traditional dishes based on raw or undercooked meat or meatderived products (especially raw sausages) play important roles in the epidemiology of the disease. Conversely, when a population consumes well-cooked meats, diagnosed cases of trichinellosis are quite rare despite persistent transmission among sylvatic hosts (Pozio, 2007). Overall, domestic pork and related products remain the most important sources of trichinellosis. This is particularly relevant when pigs are raised under free-ranging conditions or in "backyard" production facilities which allow unencumbered interactions with the local ecosystem. The second most common source of infection for humans is meat from hunted wild boars (Murrell and Pozio, 2011). Lack of education among hunters on the relationship between trichinellosis and wild game is key to the rise in trichinellosis in this subpopulation of individuals. The number of trichinellosis outbreaks involving hunters, their relatives and their friends derived from game animals (e.g., bears, cougars, foxes, walruses and wild pigs) not tested for Trichinella is on the rise (Margolis et al., 1979; Khamboonruang, 1991; Dworkin et al., 1996; Forbes, 2000; Schellenberg et al., 2003; Ancelle et al., 2005; Møller et al., 2005; Ozeretskovskaya et al., 2005; Wang et al., 2006; Sethi et al., 2010; Romano et al., 2011; Hall et al., 2012).

In France and Italy, the consumption of raw horse meat, a repast associated with regional French cuisine, has accounted for 3,334 infections in humans (2,296 in France and 1,038 in Italy) between 1975 and 2005 (Liciardi et al., 2009). In France, these outbreaks were documented in four localities, Auvergne, Ile de France, Midi Pyrenées and Provence-Alpes Côte D'Azur, where the consumption of raw horse meat is higher than in other regions of France. In Italy, human infections due to the consumption of horse meat have been documented in only two areas, the Emilia Romagna and Lombardy regions in northern Italy and the Apulia region in southern Italy. Surprisingly, the French habit of consuming raw horse meat was introduced into these regions of Italy some centuries ago (Pozio, 2001) and has carried over to modern times. 
In China and the Slovak Republic, dog meat was identified as the source of infection in several outbreaks (Dubinsky et al., 2001; Liu and Boireau, 2002). In Romania, the highest prevalence of trichinellosis in humans occurred in the Transylvanian region. Surprisingly, this high level of infection was not coincident with geographical regions harboring the highest prevalence of Trichinella infection in pigs. Rather, the prevalence was directly attributed to the habit of consuming raw meat (Blaga et al., 2007). In contrast to countries and regions where pork is a dietary mainstay, in Israel, Lebanon and Syria where the Judaic and Muslim religions forbid the consumption of pork, human outbreaks of trichinellosis have been documented only following the consumption of pork from wild boars among the Christian Arab population and immigrants from Thailand (Eisenman and Einat, 1992; Olaison and Ljungstrom, 1992; Haim et al., 1997; Hefer et al., 2004; Marva et al., 2005). Likewise, in Algeria and Senegal, where the majority of the population is Muslim, trichinellosis has been documented in Europeans (Pozio, 2007) and very rarely in the Arab population (Nezri et al., 2006). However, the Muslim population is not exempt from acquiring trichinellosis as exemplified by several outbreaks derived either from minced beef illegally mixed with pork of unknown origin, or from wild boars in Turkey (Akkoc et al., 2009; Pozio, unpublished data). Also, it should be noted that immigration of populations with ethnic food practices such as the consumption of raw meat and the illegal importation of uncontrolled meat products have resulted in new outbreaks in countries where Trichinella is considered non-endemic in the commercial pork market i.e., Denmark, Germany, Italy, Spain, Switzerland and the United Kingdom (Pozio and Marucci, 2003; Gallardo et al., 2007; Nöckler et al., 2007; Stensvold et al., 2007; Lozano Becera et al., 2012). Confusing matters further, reports of outbreaks in non-endemic areas are on the rise due to international tourists who acquired Trichinella infections abroad or hunting in areas of endemicity but who did not developed disease symptoms until returning to their home countries. In most instances, diagnosis was difficult because infections appeared as single cases (McAuley et al., 1991; Dupouy-Camet et al., 1998; Shiota et al., 1999; Nakamura et al., 2003).

\section{Future challenges with Trichinella epidemiology}

There are still tremendous gaps in our knowledge and understanding of Trichinella epidemiology such as the role of micromammals, i.e. insectivores and rodents, in the transmission cycle. If we exclude rats where their function in the domestic cycle has been investigated (Schad et al., 1987; Stojcevic et al., 2004; Pozio and Murrell, 2006; Hill et al., 2010), very limited information dating back 50 years is available on Trichinella spp. in insectivores and rodents in the wild (Rausch, 1970). Misconceptions about their importance as hosts for Trichinella resulted primarily from incorrectly identified larvae using morphometric analyses. Today using molecular techniques, we can specifically delineate nematode muscle larvae that do not belong to the genus Trichinella (Marucci et al., 2013) and begin to revisit older hypotheses. Furthermore, a huge number of individuals must be investigated to detect Trichinella infection in micromammals whereas the screening of a smaller number of carnivores is sufficient to detect a Trichinella-infected animal due to their longer life span, large size and abundance in the food chain.

Is it possible that we are seeing changes in host prevalence for $T$. nativa in the far north? Clearly, T. nativa has been well documented in walrus meat. However, this is perplexing given that walruses are for the most part bottom feeders and forage within $80 \mathrm{~m}$ of the surface. In general, adult walruses prefer molluscs but will feed on cephalopods, gastropods, crustaceans and other soft-bodied animals; they may eat $>5,000$ clams in a single feeding. In 2007,
Rausch et al. (2007) suggested that anthropogenic effects and global warming above the $10^{\circ} \mathrm{C}$ summer isotherm were causing changes in the diets of arctic mammals, in particular the Pacific walrus. The reduction in sea ice in the arctic basin and movement of the pack ice north of the upper reaches of the continental shelf during temperate seasons was modifying the behaviours and therefore the feeding habits of the Pacific walrus together with other marine mammals. As such, the eating habits of walruses have become more pelagic in recent years, feeding more frequently on ringed seals and bearded seals. Thus, with the increase in the consumption of mammals by walruses, we may see a concomitant increase in trichinellosis among indigenous peoples inhabiting the arctic coasts, predominantly those who enjoy local delicacies which involve cured or aged walrus over cooked meats. At present, we are unsure whether the increase in current reports from arctic regions is due to anthropogenic effects or to better reporting mechanisms. However, the influence of climate change on the epidemiology of Trichinella spp. as well as other zoonotic helminth fauna needs to be monitored closely as the glaciers continue to recede.

Parasites of the genus Trichinella have been documented in animals from all continents except Antarctica. According to current data, however, the geographical distribution of $T$. spiralis, the most important Trichinella sp. detected in pigs, is more confined than the distribution of domestic pigs. As such, investigations are needed to determine the extent to which $T$. spiralis is circulating among other pig populations such as feral swine in the continental United States. On a smaller, more regional scale, however, information is still lacking about Trichinella spp. circulating in localities of the world such as India and Pakistan where we can speculate that $T$. britovi and T. pseudospiralis are present. Given the newly described species, T. patagoniensis, in South America and the lack of epidemiological information preceding this finding, we can anticipate that most South American countries e.g., Bolivia, Brazil, Columbia, Ecuador, Guyana, Peru, Surinam and Venezuela, probably have T. patagoniensis circulating among wild animal populations, predominantly among felids. Given its proximity to the United States, the current "home" for T. murrelli, we also suspect that $T$. murrelli freely circulates within central America due to the absence of any physical or environmental barriers. With the recent movement of $T$. britovi into Africa, we now know that four sylvatic taxa populate this ecosystem; T. britovi, T. nelsoni, Trichinella T8 and T. zimbabwensis. In like manner, given the dissemination of T. britovi throughout the European continent and its incursion into Africa, we can speculate that $T$. britovi is likely also present in the Arabian Peninsula. We further propose that if an extensive epidemiological survey were performed, $T$. papuae would be detected in many parts of Borneo, Celebes, Java and Sumatra. Clearly these hypotheses involve speculations on our part. However, given our understanding of Trichinella transmission patterns, the age of extant species, and the paucity of epidemiological information from many regions of the world, the above projections provide reasonable hypotheses upon which to build a framework for future studies.

\section{Acknowledgements}

We are very grateful to all of the scientists who provided Trichinella spp. isolates to the International Trichinella Reference Centre during the last 25 years. Without their contribution, most of the knowledge reported in this review would not be available.

\section{References}

Airas, N., Saari, S., Mikkonen, T., Virtala, A.M., Pellikka, J., Oksanen, A., Isomursu, M. Kilpelä, S.S., Lim, C.W., Sukura, A., 2010. Sylvatic Trichinella spp. infection in Finland. J. Parasitol. 96, 67-76.

Akkoc, N., Kuruuzum, Z., Akar, S., Yuce, A., Onen, F., Yapar, N., Ozgenc, O., Turk, M., Ozdemir, D., Avci, M., Guruz, Y., Oral, A.M., Pozio, E., 2009. A large scale outbreak 
of trichinellosis due to Trichinella britovi in Turkey. Zoonoses Public Health 56, $65-70$.

Ancelle, T., 1998. History of trichinellosis outbreaks linked to horse meat consumption 1975-1998. Euro Surveill. 3, 86-89.

Ancelle, T., De Bruyne, A.E., Dupouy-Camet, J., 2005. Outbreak of trichinellosis due to consumption of bear meat from Canada, France, September 2005. Euro Surveill. 10, E051013.3

Andrassy, I., 1976. Evolution as a Basis for the Systematization of Nematodes. Pitman Publishing Ltd, London.

Andrews, J.R., Bandi, C., Pozio, E., Gomez Morales, M.A., Ainsworth, R., Abernethy, D. 1995. Identification of Trichinella pseudospiralis from a human case using random amplified polymorphic DNA. Am. J. Trop. Med. Hyg. 53, 185-188.

Anonymous, 1964. Summary of the discussion. In: Corradetti, A. (Ed.), Proceedings of the 1st International Congress of Parasitology, Rome, September 21-26. Tamburini Editore, Milan, p. 697.

Anonymous, 2006. Outbreak of trichinellosis in French hunters who ate Canadian black bear meat. Can. Commun. Dis. Rep. 32, 109-112.

Bandi, C., La Rosa, G., Bardin, M.G., Damiani, G., Comincini, S., Tasciotti, L., Pozio, E. 1995. Random amplified polymorphic DNA fingerprints of the eight taxa of Trichinella and their comparison with allozyme analysis. Parasitology 110, 401407.

Beck, R., Beck, A., Kusak, J., Mihaljević, Z., Lucinger, S., Zivicnjak, T., Huber, D., Gudan, A., Marinculić, A., 2009a. Trichinellosis in wolves from Croatia. Vet. Parasitol. $159,308-311$

Beck, R., Beck, A., Lucinger, S., Florijancić, T., Bosković, I., Marinculić, A., 2009b. Trichinella pseudospiralis in pig from Croatia. Vet. Parasitol. 159, 304-307.

Blaga, R., Durand, B., Antoniu, S., Gherman, C., Cretu, C.M., Cozma, V., Boireau, P.A 2007. Dramatic increase in the incidence of human trichinellosis in Romania over the past 25 years: impact of political changes and regional food habits. Am. J. Trop. Med. Hyg. 76, 983-986.

Blaga, R., Gherman, C., Cozma, V., Zocevic, A., Pozio, E., Boireau, P., 2009. Trichinella species circulating among wild and domestic animals in Romania. Vet. Parasitol. $159,218-221$.

Blaxter, M.L., De Ley, P., Garey, J.R., Liu, L.X., Scheldeman, P., Vierstraete, A. Vanfleteren, J.R., Mackey, L.Y., Dorris, M., Frisse, L.M., Vida, J.T., Thomas, W.K. 1998. A molecular evolutionary framework for the phylum Nematoda. Nature 392, 71-75.

Britov, V.A., 1997. Trichinellosis in Kamchatka. Wiad. Parazytol. 43, 287-288.

Britov, V.A., Boev, S.N., 1972. Taxonomic rank of various strains of Trichinella and their circulation in nature. Vestnik Akademii Nauk KSSR 28, 27-32.

Burke, R., Masuoka, P., Murrell, K.D., 2008. Swine Trichinella infection and geographic information system tools. Emerg. Infect. Dis. 14, 1109-1111.

Campbell, W.C., 1983. Modes of transmission. In: Campbell, W.C. (Ed.), Trichinella and Trichinosis. Plenum Press, London, United Kingdom, pp. 425-444.

Campbell, W.C., Pozio, E., Bruschi, F. (Eds.), 1994. Trichinellosis. ISS Press, Rome.

Chmurzyńska, E., Różycki, M., Bilska-Zając, E., Nöckler, K., Mayer-Scholl, A., Pozio, E. Cencek, T., Karamon, J., in press. Trichinella nativa in red foxes (Vulpes vulpes) of Germany and Poland: possible different origins. Vet. Parasitol.

Cuttell, L., Cookson, B., Jackson, L.A., Gray, C., Traub, R.J., 2012. First report of a Trichinella papuae infection in a wild pig (Sus scrofa) from an Australian island in the Torres Strait region. Vet. Parasitol. 185, 343-345.

Dame, J.B., Blouin, M.S., Courtney, C.H., 1993. Genetic structure of populations of Ostertagia ostertagi. Vet. Parasitol. 46, 55-62.

Davidson, R.K., Gjerde, B., Vikøren, T., Lillehaug, A., Handeland, K., 2006. Prevalence of Trichinella larvae and extra-intestinal nematodes in Norwegian red foxes (Vulpes vulpes). Vet. Parasitol. 136, 307-316.

Dea-Ayuela, M.A., Bolás-Fernández, F., 2005. Two-dimensional electrophoresis and mass spectrometry for the identification of species-specific Trichinella antigens. Vet. Parasitol. 132, 43-49.

Despommier, D.D., 1998. How does Trichinella spiralis make itself at home? Parasitol. Today $14,318-323$.

Dick, T.A., 1983. Species, and infraspecific variation. In: Campbell, W.C. (Ed.) Trichinella and Trichinosis. Plenum Press, New York and London, pp. 31-73.

Dick, T.A., Pozio, E., 2001. Trichinella spp. and trichinellosis. In: Samuel, W.M., Pybus, M.J., Kocan, A.A. (Eds.), Parasitic Diseases of Wild Mammals, second ed. Iowa State University Press, Ames, pp. 380-396.

Dubinsky, P., Stefancikova, A., Kincekova, J., Ondriska, F., Reiterova, K., Medvedova M., 2001. Trichinellosis in the Slovak Republic. Parasite 8 (S2), 100-102.

Dunams-Morel, D.B., Reichard, M.V., Torretti, L., Zarlenga, D.S., Rosenthal, B.M., 2012. Discernible but limited introgression has occurred where Trichinella nativa and the T6 genotype occur in sympatry. Infect. Genet. Evol. 12, 530-538.

Dupouy-Camet, J., 2000. Trichinellosis: a worldwide zoonosis. Vet. Parasitol. 93, 191-200.

Dupouy-Camet, J., Allegretti, S., Truong, T.P., 1998. Enquete sur l'incidence de la trichinellose en France (1994-1995). Bull. Epidemiol. Hebd. 28, 122-123.

Dworkin, M.S., Gamble, H.R., Zarlenga, D.S., Tennican, P.O., 1996. Outbreak of trichinellosis associated with eating cougar jerky. J. Infect. Dis. 174, 663-666.

Eisenman, A., Einat, R., 1992. A family outbreak of trichinosis acquired in Israel. Harefuah 122, 702-704 (In Hebrew)

Fonseca-Salamanca, F., Nogal-Ruiz, J.J., García-Sánchez, R.N., Bolas-Fernandez, F. Jiménez S Alamo, R Garate, T, Martínez-Fernandez, A.R. 2009. Prevalence of Trichinella spp. in North Spain wild fauna and new variety of Trichinella britovi identification. Vet. Parasitol. 159, 222-224.

Forbes, L.B., 2000. The occurrence and ecology of Trichinella in marine mammals. Vet. Parasitol. 93, 321-334.
Frey, C.F., Schuppers, M.E., Müller, N., Ryser-Degiorgis, M.P., Gottstein, B., 2009. Assessment of the prevalence of Trichinella spp. in red foxes and Eurasian lynxes from Switzerland. Vet. Parasitol. 159, 295-299.

Fu, B.Q., Liu, M.Y., Yao, C.Y., Li, W.H., Li, Y.G., Wang, Y.H., Wu, X.P., Zhang, D.L., Cai, X.P., Blaga, R., Boireau, P., 2009. Species identification of Trichinella isolates from China. Vet. Parasitol. 159, 214-217.

Gajadhar, A.A., Forbes, L.B., 2010. A 10-year wildlife survey of 15 species of Canadian carnivores identifies new hosts or geographic locations for Trichinella genotypes T2, T4, T5, and T6. Vet. Parasitol. 168, 78-83.

Gallardo, M.T., Mateos, L., Artieda, J., Wesslen, L., Ruiz, C., Garcia, M.A., GalmesTruyols, A., Martin, A., Hernandez-Pezzi, G., Andersson, Y., Garate, T., Christensson, D., 2007. Outbreak of trichinellosis in Spain and Sweden due to consumption of wild boar meat contaminated with Trichinella britovi. Euro Surveill. 12, E070315.1.

García-Sánchez, R.N., Nogal-Ruiz, J.J., Manzano-Lorenzo, R., Díaz, J.M., López, G.P., Ruano, F.J., Casas, A.R., Bascón, C.C., Bolás-Fernández, F. Martínez-Fernández. A.R., 2009. Trichinellosis survey in the wild boar from the Toledo mountains in south-western Spain (2007-2008): molecular characterization of Trichinella isolates by ISSR-PCR. J. Helminthol. 83, 117-120.

Garkavi, B.L., 1972. Species of Trichinella isolated from wild animals. Veterinariya $10,90-91$

Gasser, R.B., Zhu, X.Q., Monti, J.R., Dou, L., Cai, X., Pozio, E., 1998. PCR-SSCP of rDNA for the identification of Trichinella isolates from mainland China. Mol. Cell. Probes 12, 27-34.

Gasser, R.B., Hu, M., Abs EL-Osta, Y.G., Zarlenga, D.S., Pozio, E., 2004. Non-isotopic single-strand conformation polymorphism analysis of sequence variability in ribosomal DNA expansion segments within the genus Trichinella (Nematoda: Adenophorea). Electrophoresis 25, 3357-3364.

Gómez-Morales, M.A., Ludovisi, A., Amati, M., Blaga, R., Zivojinovic, M., Ribicich, M., Pozio, E., 2012. A distinctive Western blot pattern to recognize Trichinella infections in humans and pigs. Int. J. Parasitol. 42, 1017-1023.

Gould, S.E., 1970. History. In: Gould, S.E. (Ed.), Trichinosis in Man and Animals. Thomas C.C. Publisher, Springfield, Illinois, pp. 3-18.

Haim, M., Efrat, M., Wilson, M., Schantz, P.M., Cohen, D., Shemer, J., 1997. An outbreak of Trichinella spiralis infection in southern Lebanon. Epidemiol. Infect. $119,357-362$

Hall, R.L., Lindsay, A., Hammond, C., Montgomery, S.P., Wilkins, P.P., da Silva, A.J., McAuliffe, I., de Almeida, M., Bishop, H., Mathison, B., Sun, B., Largusa, R., Jones, J.L., 2012. Outbreak of human trichinellosis in Northern California caused by Trichinella murrelli. Am. J. Trop. Med. Hyg. 87, 297-302.

Hefer, E., Rishpon, S., Volovik, I., 2004. Trichinosis outbreak among Thai immigrant workers in the Hadera sub-district. Harefuah 143, 656-660 (In Hebrew).

Heptner, V.G., Naumov, N.P., 1998. Mammals of the Soviet Union. Sirenia and Carnivora (Sea cows, Wolves and Bears), vol. II, Part 1a. Science Publishers, Inc, USA

Hill, D.E., Pierce, V., Murrell, K.D., Ratliffe, N., Rupp, B., Fournet, V.M., Zarlenga, D.S., Rosenthal, B.M., Gamble, H.R., Kelly, K., Dulin, M., 2010. Cessation of Trichinella spiralis transmission among scavenging mammals after the removal of infected pigs from a poorly managed farm: implications for trichinae transmission in the US. Zoonoses Public Health 57, e116-e123.

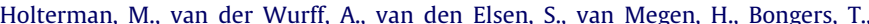
Holovachov, O., Bakker, J., Helder, J., 2006. Phylum-wide analysis of SSU rDNA reveals deep phylogenetic relationships among nematodes and accelerated evolution toward crown clades. Mol. Biol. Evol. 23, 1792-1800.

Houzé, S., Ancelle, T., Matra, R., Boceno, C., Carlier, Y., Gajadhar, A.A., Dupouy-Camet, J., 2009. Trichinellosis acquired in Nunavut, Canada in September 2009: meat from grizzly bear suspected. Euro Surveill., 14

Hurníková, Z., Dubinský, P., 2009. Long-term survey on Trichinella prevalence in wildlife of Slovakia. Vet. Parasitol. 159, 276-280.

Hurníková, Z., Dubinský, P., Mukaratirwa, S., Foggin, C.M., Kapel, C.M.O., 2004. Infectivity and temperature tolerance of non-encapsulating Trichinella zimbabwensis in experimentally infected red foxes (Vulpes vulpes). Helminthologia 41, 189-192.

Intapan, P.M., Chotmongkol, V., Tantrawatpan, C., Sanpool, O., Morakote, N., Maleewong. W. 2011. Molecular identification of Trichinella papuae from a Thai patient with imported trichinellosis. Am. J. Trop. Med. Hyg. 84, 994-997.

Jongwutiwes, S., Chantachum, N., Kraivichian, P., Siriyasatien, P., Putaporntip, C., Tamburrini, A., La Rosa, G., Sreesunpasirikul, C., Yingyourd, P., Pozio, E. 1998. First outbreak of human trichinellosis caused by Trichinella pseudospiralis. Clin. Infect. Dis. 26, 111-115.

Kanai, Y., Inoue, T., Mano, T., Nonaka, N., Katakura, K., Oku, Y., 2007. Epizootiological survey of Trichinella spp. infection in carnivores, rodents and insectivores in Hokkaido, Japan. Jpn. J. Vet. Res. 54, 175-182.

Khamboonruang, C., 1991. The present status of trichinellosis in Thailand. Southeast Asian J. Trop. Med. Public Health 22, 312-315.

Khumjui, C., Choomkasien, P., Dekumyoy, P., Kusolsuk, T., Kongkaew, W., Chalamaat, M., Jones, J.L., 2008. Outbreak of trichinellosis caused by Trichinella papuae, Thailand, 2006. Emerg. Infect. Dis. 14, 1913-1915.

Kim, C.W., 1983. Geographic distribution and prevalence. In: Campbell, W.C. (Ed.), Trichinella and Trichinosis. Plenum Press, New York and London, pp. 445-500.

Krivokapich, S.J., Molina, V., Bergagna, H.F., Guarnera, E.A., 2006. Epidemiological survey of Trichinella infection in domestic, synanthropic and sylvatic animals from Argentina. J. Helminthol. 80, 267-269.

Krivokapich, S.J., Prous, C.L., Gatt, G.M., Confalonieri, V., Molina, V., Matarasso, H., Guarnera, E., 2008. Molecular evidence for a novel encapsulated genotype of Trichinella from Patagonia, Argentina. Vet. Parasitol. 156, 234-240. 
Krivokapich, S.J., Pozio, E., Gatti, G.M., Prous, C.L., Ribicich, M., Marucci, G., La Rosa, G., Confalonieri, V., 2012. Trichinella patagoniensis n. sp. (Nematoda), a new encapsulated species infecting carnivorous mammals in South America. Int. J. Parasitol. 42, 903-910.

Kusolsuk, T., Kamonrattanakun, S., Wesanonthawech, A., Dekumyoy, P., Thaenkham, U., Yoonuan, T., Nuamtanong, S., Sa-Nguankiat, S., Pubampen, S., Maipanich, W., Panitchakit, J., Marucci, G., Pozio, E., Waikagul, J., 2010. The second outbreak of trichinellosis caused by Trichinella papuae in Thailand. Trans. R. Soc. Trop. Med. Hyg. 104, 433-437.

La Grange, L.J., Marucci, G., Pozio, E., 2009. Trichinella zimbabwensis in wild Nile crocodiles (Crocodylus niloticus) of South Africa. Vet. Parasitol. 161, 88-91.

La Grange, L.J., Marucci, G., Pozio, E., 2010. Trichinella zimbabwensis in a naturally infected mammal. J. Helminthol. 84, 35-38.

La Grange, L.J., Govender, D., Mukaratirwa, S., 2013. The occurrence of Trichinella zimbabwensis in naturally infected wild crocodiles (Crocodylus niloticus) from the Kruger National Park, South Africa. J. Helminthol. 16, 1-6.

La Rosa, G., Pozio, E., Rossi, P., Murrell, K.D., 1992. Allozyme analysis of Trichinella isolates from various host species and geographic regions. J. Parasitol. 78, 641646.

La Rosa, G., Marucci, G., Zarlenga, D.S., Pozio, E., 2001. Trichinella pseudospiralis populations of the Palearctic region and their relationship with populations of the Nearctic and Australian regions. Int. J. Parasitol. 31, 297-305.

La Rosa, G., Marucci, G., Zarlenga, D.S., Casulli, A., Zarnke, R.L., Pozio, E., 2003a. Molecular identification of natural hybrids between Trichinella nativa and Trichinella T6 provides evidence of gene flow and ongoing genetic divergence. Int. J. Parasitol. 33, 209-216.

La Rosa, G., Marucci, G., Pozio, E., 2003b. Biochemical analysis of encapsulated and non-encapsulated species of Trichinella (Nematoda, Trichinellidae) from coldand warm-blooded animals reveals a high genetic divergence in the genus. Parasitol. Res. 91, 462-466.

La Rosa, G., Marucci, G., Rosenthal, B.M., Pozio, E., 2012. Development of a single larva microsatellite analysis to investigate the population structure of Trichinella spiralis. Infect. Genet. Evol. 12, 369-376.

Larrat, S., Simard, M., Lair, S., Bélanger, D., Proulx, J.F., 2012. From science to action and from action to science: the Nunavik Trichinellosis Prevention Program. Int. J. Circumpolar Health 71, 18595.

Lichtenfels, J.R., Murrell, K.D., Pilitt, P.A., 1983. Comparison of three subspecies of Trichinella spiralis by scanning electron microscopy. J. Parasitol. 69, 1131-1140.

Liciardi, M., Marucci, G., Addis, G., Ludovisi, A., Gomez Morales, M.A., Deiana, B., Cabaj, W., Pozio, E., 2009. Trichinella britovi and Trichinella spiralis mixed infection in a horse from Poland. Vet. Parasitol. 161, 345-348.

Liu, M., Boireau, P., 2002. Trichinellosis in China: epidemiology and control. Trends Parasitol. 18, 553-556.

Liu, X., Song, Y., Lu, H., Tang, B., Piao, X., Hou, N., Peng, S., Jiang, N., Yin, J., Liu, M., Chen, Q., 2011. Transcriptome of small regulatory RNAs in the development of the zoonotic parasite Trichinella spiralis. PLoS ONE 6, e26448.

Liu, X., Song, Y., Jiang, N., Wang, J., Tang, B., Lu, H., Peng, S., Chang, Z., Tang, Y., Yin, J., Liu, M., Tan, Y., Chen, Q., 2012. Global gene expression analysis of the zoonotic parasite Trichinella spiralis revealed novel genes in host parasite interaction. PLoS Negl. Trop. Dis. 6, e1794.

Lo, Y.C., Hung, C.C., Lai, C.S., Wu, Z., Nagano, I., Maeda, T., Takahashi, Y., Chiu, C.H., Shyong Jiang, D.D., 2009. Human trichinosis after consumption of soft-shelled turtles, Taiwan. Emerg. Infect. Dis. 15, 2056-2058.

Lozano Becera, J.C., Gurtner De la Fuente, V., Pozio, E., Bernasconi, E., 2012. Trichinellosis in immigrants in Switzerland. J. Travel Med. 19, 195-197.

Malakauskas, A., Paulauskas, V., Järvis, T., Keidans, P., Eddi, C., Kapel, C.M., 2007. Molecular epidemiology of Trichinella spp. in three Baltic countries: Lithuania, Latvia, and Estonia. Parasitol. Res. 100, 687-693.

Margolis, H.S., Middaugh, J.P., Burgess, R.D., 1979. Arctic trichinosis: two Alaskan outbreaks from walrus meat. J. Infect. Dis. 139, 102-105

Marucci, G., La Grange, L.J., La Rosa, G., Pozio, E., 2009. Trichinella nelsoni and Trichinella T8 mixed infection in a lion (Panthera leo) of the Kruger National Park (South Africa). Vet. Parasitol. 159, 225-228.

Marucci, G., Interisano, M., La Rosa, G., Pozio, E., 2013. Molecular identification of nematode larvae different from those of the Trichinella genus detected by muscle digestion. Vet. Parasitol. 194, 117-120.

Marva, E., Markovics, A., Gdalevich, M., Asor, N., Sadik, C., Leventhal, A., 2005. Trichinellosis outbreak. Emerg. Infect. Dis. 11, 1979-1981.

Masuoka, P.M., Burke, R., Colaccico, M., Razuri, H., Hill, D., Murrell, K.D., 2009. Predicted geographic ranges for North American sylvatic Trichinella species. J. Parasitol. 95, 829-837.

McAuley, J.B., Michelson, M.K., Schantz, P.M., 1991. Trichinella infection in travelers. J. Infect. Dis. 164, 1013-1016.

Meldal, B.H., Debenham, N.J., De Ley, P., De Ley, I.T., Vanfleteren, J.R., Vierstraete, A.R., Bert, W., Borgonie, G., Moens, T., Tyler, P.A. Austen, M.C., Blaxter, M.L., Rogers, A.D., Lambshead, P.J., 2007. An improved molecular phylogeny of the Nematoda with special emphasis on marine taxa. Mol. Phylogenet. Evol. 42, 622-636.

Mitreva, M., Jasmer, D.P., 2008. Advances in the sequencing of the genome of the adenophorean nematode Trichinella spiralis. Parasitology 135, 869-880.

Mitreva, M., Jasmer, D.P., 2010. Trichinella spiralis: genomic application to control a zoonotic nematode. Infect. Disord. Drug Targets 10, 376-384.

Mitreva, M., Jasmer, D.P., Appleton, J., Martin, J., Dante, M., Wylie, T., Clifton, S.W., Waterston, R.H., McCarter, J.P., 2004. Gene discovery in the adenophorean nematode Trichinella spiralis: an analysis of transcription from three life cycle stages. Mol. Biochem. Parasitol. 137, 277-291.
Mitreva, M., Appleton, J., McCarter, J.P., Jasmer, D.P., 2005. Expressed sequence tags from life cycle stages of Trichinella spiralis: application to biology and parasite control. Vet. Parasitol. 132, 13-17.

Mitreva, M., Jasmer, D.P., Zarlenga, D.S., Wang, Z., Abubucker, S., Martin, J., Taylor, C.M., Yin, Y., Fulton, L., Minx, P., Yang, S.P., Warren, W.C., Fulton, R.S., Bhonagiri, V., Zhang, X., Hallsworth-Pepin, K., Clifton, S.W., McCarter, J.P., Appleton, J., Mardis, E.R., Wilson, R.K., 2011. The draft genome of the parasitic nematode Trichinella spiralis. Nat. Genet. 43, 228-235.

Møller, L.N., Petersen, E., Kapel, C.M., Melbye, M., Koch, A., 2005. Outbreak of trichinellosis associated with consumption of game meat in West Greenland. Vet. Parasitol. 132, 131-136.

Mowlavi, G., Marucci, G., Mobedi, I., Zahabiioon, F., Mirjalali, H., Pozio, E., 2009 Trichinella britovi in a leopard (Panthera pardus saxicolor) in Iran. Vet. Parasitol. 164, 350-352.

Mukaratirwa, S., Foggin, C.M., 1999. Infectivity of Trichinella sp. isolated from Crocodylus niloticus to the indigenous Zimbabwean pig (Mukota). Int. J. Parasitol. 29, 1129-1131.

Mukaratirwa, S., Dzoma, B.M., Matenga, E., Ruziwa, S.D., Sacchi, L., Pozio, E., 2008 Experimental infections of baboons (Papio spp.) and vervet monkeys (Cercopithecus aethiops) with Trichinella zimbabwensis and successful treatment with ivermectin. Onderstepoort J. Vet. Res. 75, 173-180.

Mukaratirwa, S., La Grange, L., Pfukenyi, D.M., 2013. Trichinella infections in animals and humans in sub-Saharan Africa: a review. Acta Trop. 125, 82-89.

Murrell, K.D., Pozio, E., 2011. Worldwide occurrence and impact of human trichinellosis, 1986-2009. Emerg. Infect. Dis. 17, 2194-2202.

Nagano, I., Wu, Z., Matsuo, A., Pozio, E., Takahashi, Y., 1999. Identification of Trichinella isolates by polymerase chain reaction-restriction fragment length polymorphism of the mitochondrial cytochrome c-oxidase subunit I gene. Int. J Parasitol. 29, 1113-1120.

Nakamura, T., Miura, T., Nakaoka, T., Nagano, I., Takahashi, Y., Iwamoto, A., 2003. A case of trichinellosis with spontaneous remission. Kansenshogaku Zasshi 77, 839-843 (In Japanese).

Nezri, M., Rue, J., De Bruyne, A., Cohen-Valensi, R., Pozio, E., Dupouy-Camet, J., 2006 Premiere observation d'un cas de humain de trichinellose a Trichinella britovi en Algerie apre's consummation de viande de chacal (Canis aureus). Bull. Soc. Pathol. Exot. 99, 94-95.

Nöckler, K., Serrano, F.J., Boireau, P., Kapel, C.M., Pozio, E., 2005. Experimental studies in pigs on Trichinella detection in different diagnostic matrices. Vet. Parasitol. 132, 85-90.

Nöckler, K., Wichmann-Schauer, H., Hiller, P., Müller, A, Bogner, K.H., 2007. Trichinellosis outbreak in Bavaria caused by cured sausage from Romania, January 2007. Euro Surveill. 12, EO70823.2.

Oivanen, L., Kapel, C.M., Pozio, E., La Rosa, G., Mikkonen, T., Sukura, A., 2002. Associations between Trichinella species and host species in Finland. J. Parasitol. 88, 84-88.

Olaison, L., Ljungstrom, I., 1992. An outbreak of trichinosis in Lebanon. Trans. R. Soc. Trop. Med. Hyg. 86, 658-660.

Owen, I.L., Reid, S.A., 2007. Survival of Trichinella papuae muscle larvae in a pig carcass maintained under simulated natural conditions in Papua New Guinea. J. Helminthol. 81, 429-432.

Owen, I.L., Sims, L.D., Wigglesworth, M.C., Puana, I., 2000. Trichinellosis in Papua New Guinea. Aust. Vet. J. 78, 698-701.

Ozeretskovskaya, N.N., Mikhailova, L.G., Sabgaida, T.P., Dovgalev, A.S., 2005. New trends and clinical patterns of human trichinellosis in Russia at the beginning of the XXI century. Vet. Parasitol. 132, 167-171.

Pannwitz, G., Mayer-Scholl, A., Balicka-Ramisz, A., Nöckler, K., 2010. Increased prevalence of Trichinella spp., Northeastern Germany, 2008. Emerg. Infect. Dis. 16, 936-942.

Perteguer, M.J., Rodríguez, E., García-Sánchez, R.N., Nogal-Ruiz, J.J., Bolas-Fernández, F., Martínez-Fernández, A.R., Gárate, T., 2009. Identification of Spanish Trichinella isolates by ISSR-PCR: intra-specific variability of Trichinella britovi. Vet. Parasitol. 159, 206-209.

Pozio, E., 2001. New patterns of Trichinella infections. Vet. Parasitol. 98, 133-148.

Pozio, E., 2005. The broad spectrum of Trichinella hosts: from cold- to warmblooded animals. Vet. Parasitol. 132, 3-11.

Pozio, E., 2007. World distribution of Trichinella spp. infections in animals and humans. Vet. Parasitol. 149, 3-21.

Pozio, E., La Rosa, G., 2000. Trichinella murrelli n. sp: etiological agent of sylvatic trichinellosis in temperate areas of North America. J. Parasitol. 86, 134-139.

Pozio, E., La Rosa, G., 2003. PCR-derived methods for the identification of Trichinella parasites from animal and human samples. Methods Mol. Biol. 216, 299-309.

Pozio, E., Marucci, G., 2003. Trichinella-infected pork products: a dangerous gift. Trends Parasitol. 19, 338.

Pozio, E., Murrell, K.D., 2006. Systematics and epidemiology of Trichinella. Adv. Parasitol. 63, 367-439.

Pozio, E., Zarlenga, D.S., 2005. Recent advances on the taxonomy, systematics and epidemiology of Trichinella. Int. J. Parasitol. 35, 1191-1204.

Pozio, E., La Rosa, G., Murrell, K.D., Lichtenfels, J.R., 1992. Taxonomic revision of the genus Trichinella. J. Parasitol. 78, 654-659.

Pozio, E., De Meneghi, D., Roelke-Parker, M.E., La Rosa, G., 1997b. Trichinella nelsoni in carnivores from the Serengeti ecosystem, Tanzania. J. Parasitol. 83, 11951198.

Pozio, E., Serrano, F.J., La Rosa, G., Reina, D., Perez-Martin, E., Navarrete, I., 1997a. Evidence of potential gene flow in Trichinella spiralis and in Trichinella britovi in nature. J. Parasitol. 83, 163-166. 
Pozio, E., Miller, I., Järvis, T., Kapel, C.M., La Rosa, G., 1998. Distribution of sylvatic species of Trichinella in Estonia according to climate zones. J. Parasitol. 84, 193195.

Pozio, E., Owen, I.L., La Rosa, G., Sacchi, L., Rossi, P., Corona, S., 1999a. Trichinella papuae n.sp. (Nematoda), a new non-encapsulated species from domestic and sylvatic swine of Papua New Guinea. Int. J. Parasitol. 29, 1825-1839.

Pozio, E., Kapel, C.M., Gamble, H.R., 1999b. Specificity and sensitivity of random amplified polymorphic DNA analysis for the identification of single larvae of Trichinella after experimental infection of pigs. Parasitol. Res. 85, 504-506.

Pozio, E., Foggin, C.M., Marucci, G., La Rosa, G., Sacchi, L., Corona, S., Rossi, P., Mukaratirwa, S., 2002. Trichinella zimbabwensis n.sp. (Nematoda), a new nonencapsulated species from crocodiles (Crocodylus niloticus) in Zimbabwe also infecting mammals. Int. J. Parasitol. 32, 1787-1799.

Pozio, E., Marucci, G., Casulli, A., Sacchi, L., Mukaratirwa, S., Foggin, C.M., La Rosa, G., 2004. Trichinella papuae and Trichinella zimbabwensis induce infection in experimentally infected varans, caimans, pythons and turtles. Parasitology $128,333-342$.

Pozio, E., Owen, I.L., Marucci, G., La Rosa, G., 2005a. Inappropriate feeding practice favors the transmission of Trichinella papuae from wild pigs to saltwate crocodiles in Papua New Guinea. Vet. Parasitol. 127, 245-251.

Pozio, E., Pagani, P., Marucci, G., Zarlenga, D.S., Hoberg, E.P., De Meneghi, D., La Rosa G., Rossi, L., 2005b. Trichinella britovi etiological agent of sylvatic trichinellosis in the Republic of Guinea (West Africa) and a re-evaluation of geographical distribution for encapsulated species in Africa. Int. J. Parasitol. 35, 955-960.

Pozio, E., Foggin, C.M., Gelanew, T., Marucci, G., Hailu, A., Rossi, P., Gomez Morales M.A., 2007. Trichinella zimbabwensis in wild reptiles of Zimbabwe and Mozambique and farmed reptiles of Ethiopia. Vet. Parasitol. 143, 305-310.

Pozio, E., Hoberg, E., La Rosa, G., Zarlenga, D.S., 2009a. Molecular taxonomy, phylogeny and biogeography of nematodes belonging to the Trichinella genus. Infect. Genet. Evol. 9, 606-616.

Pozio, E., Rinaldi, L., Marucci, G., Musella, V., Galati, F., Cringoli, G., Boireau, P., La Rosa, G., 2009b. Hosts and habitats of Trichinella spiralis and Trichinella britovi in Europe. Int. J. Parasitol. 39, 71-79.

Proulx, J.F., MacLean, J.D., Gyorkos, T.W., Leclair, D., Richter, A.K., Serhir, B., Forbes, L., Gajadhar, A.A., 2002. Novel prevention program for trichinellosis in Inuit communities. Clin. Infect. Dis. 34, 1508-1514.

Rafter, P., Marucci, G., Brangan, P., Pozio, E., 2005. Rediscovery of Trichinella spiralis in red foxes (Vulpes vulpes) in Ireland after 30 years of oblivion. J. Infect. 50, 61 65.

Ranque, S., Faugère, B., Pozio, E., La Rosa, G., Tamburrini, A., Pellissier, J.F., Brouqui, P., 2000. Trichinella pseudospiralis outbreak in France. Emerg. Infect. Dis. 6, 543 547.

Rausch, R.L., 1970. Trichinosis in the Arctic. In: Gould, S.E. (Ed.), Trichinosis in Man and Animals. Charles C. Thomas Publisher, Springfield, Illinois, pp. 348-373.

Rausch, R.L., George, J.C., Brower, H.K., 2007. Effect of climatic warming on the Pacific walrus, and potential modification of its helminth fauna. J. Parasitol. 93, 1247-1251.

Reichard, M.V., Torretti, L., Snider, T.A., Garvon, J.M., Marucci, G., Pozio, E., 2008. Trichinella T6 and Trichinella nativa in wolverines (Gulo gulo) from Nunavut Canada. Parasitol. Res. 103, 657-661.

Reichard, M.V., Tiernan, K.E., Paras, K.L., Interisano, M., Reiskind, M.H., Panciera, R.J. Pozio, E., 2011. Detection of Trichinella murrelli in coyotes (Canis latrans) from Oklahoma and North Texas. Vet. Parasitol. 182, 368-371.

Ribicich, M., Gamble, H.R., Bolpe, J., Scialfa, E., Krivokapich, S., Cardillo, N., Betti, A. Holzmann, M.L., Pasqualetti, M., Fariña, F., Rosa, A., 2010. Trichinella infection in wild animals from endemic regions of Argentina. Parasitol. Res. 107, 377-380.

Robinson, M.W., Connolly, B., 2005. Proteomic analysis of the excretory-secretory proteins of the Trichinella spiralis L1 larva, a nematode parasite of skeletal muscle. Proteomics 5, 4525-4532.

Robinson, M.W., Greig, R., Beattie, K.A., Lamont, D.J., Connolly, B., 2007. Comparative analysis of the excretory-secretory proteome of the muscle larva of Trichinella pseudospiralis and Trichinella spiralis. Int. J. Parasitol. 37, 139-148.

Romano, F., Motta, A., Melino, M., Negro, M., Gavotto, G., Decasteli, L., Careddu, E. Bianchi, C., Bianchi, D.M., Pozio, E., 2011. Investigation on a focus of human trichinellosis revealed by an atypical clinical case after wild-boar (Sus scrofa) pork consumption in northern Italy. Parasite 18, 85-87.

Rosenthal, B.M., La Rosa, G., Zarlenga, D., Dunams, D., Chunyu, Y., Mingyuan, L. Pozio, E., 2008. Human dispersal of Trichinella spiralis in domesticated pigs. Infect. Genet. Evol. 8, 799-805.
Schad, G.A., Duffy, C.H., Leiby, D.A., Murrell, K.D., Zirkle, E.W., 1987. Trichinella spiralis in an agricultural ecosystem: transmission under natural and experimentally modified on-farm conditions. J. Parasitol. 73, 95-102.

Schellenberg, R.S., Tan, B.J., Irvine, J.D., Stockdale, D.R., Gajadhar, A.A., Serhir, B., Botha, J., Armstrong, C.A., Woods, S.A., Blondeau, J.M., McNab, T.L., 2003. An outbreak of trichinellosis due to consumption of bear meat infected with Trichinella nativa, in 2 northern Saskatchewan communities. J. Infect. Dis. 188, 835-843.

Schnurenberger, P.R., Masterson, R.A., Suessenguth, H., Basshe Jr., Wj., 1964. Swine trichinosis. I. Fecal transmission under simulated field conditions. Am. J. Vet. Res. 25, 174-178.

Serhir, B., MacLean, J.D., Healey, S., Segal, B., Forbes, L., 2001. Outbreak of trichinellosis associated with arctic walruses in northern Canada, 1999. Can. Commun. Dis. Rep. 27, 31-36.

Sethi, B., Butola, K.S., Arora, B., Kumar, Y., Suri, V., 2010. Human trichinosis in remotes of Uttarakhand, India. Indian J. Med. Sci. 64, 104-110.

Shaikenov, B., 1992. Ecological border of distribution of Trichinella nativa Britov et Boev, 1972 and T. nelsoni Britov et Boev, 1972. Wiad. Parazytol. 38, 85-91.

Shaikenov, B.S., Boev, S.N., 1983. Distribution of Trichinella species in the old world. Wiad. Parazytol. 29, 595-608.

Shiota, T., Arizono, N., Yoshioka, T., Ishikawa, Y., Fujitake, J., Fujii, H., Tatsuoka, Y., Kim, Y., 1999. Imported trichinellosis with severe myositis-report of a case. Kansenshogaku Zasshi 73, 76-82 (In Japanese).

Stensvold, C.R., Nielsen, H.V., Molbak, K., 2007. A case of trichinellosis in Denmark, imported from Poland, June 2007. Euro Surveill. 12, E070809.3.

Stewart, G.L., Kennedy, R.R., Larsen, E., 1990. Infectivity of Trichinella pseudospiralis isolated from carrion. J. Parasitol. 76, 750-751.

Stojcevic, D., Zivicnjak, T., Marinculic, A., Marucci, G., Andelko, G., Brstilo, M., Pavo, L., Pozio, E., 2004. The epidemiological investigation of Trichinella infection in brown rats (Rattus norvegicus) and domestic pigs in Croatia suggests that rats are not a reservoir at the farm level. J. Parasitol. 90, 666-670.

Wang, Z.Q., Cui, J., Xu, B.L., 2006. The epidemiology of human trichinellosis in China during 2000-2003. Acta Trop. 97, 247-251.

Wang, Z., Zarlenga, D., Martin, J., Abubucker, S., Mitreva, M., 2012a. Exploring metazoan evolution through dynamic and holistic changes in protein families and domains. BMC Evol. Biol. 12, 138.

Wang, Z.Q., Li, L.Z., Jiang, P., Liu, L.N., Cui, J., 2012b. Molecular identification and phylogenetic analysis of Trichinella isolates from different provinces in mainland China. Parasitol. Res. 110, 753-757.

Wang, Z.Q., Wang, L., Cui, J., 2012c. Proteomic analysis of Trichinella spiralis proteins in intestinal epithelial cells after culture with their larvae by shotgun LC-MS/ MS approach. J. Proteomics 75, 2375-2383.

Webster, P., Malakauskas, A., Kapel, C.M., 2002. Infectivity of Trichinella papuae for experimentally infected red foxes (Vulpes vulpes). Vet. Parasitol. 105, 215-218.

Wu, Z., Snabel, V., Pozio, E., Hurnikova, Z., Nareaho, A., Nagano, I., Takahashi, Y., 2007. Genetic relationships among Trichinella pseudospiralis isolates from Australian, Nearctic, and Palearctic regions. Parasitol. Res. 101, 1567-1573.

Yoshida, T.H., 1980. Cytogenetics of the Black Rat: Karyotype Evolution and Species Differentiation. University of Tokyo Press, Tokyo.

Zarlenga, D.S., 1998. Molecular aspects of speciation in the genus Trichinella. In: Ortega-Pierres, G., Gamble, R., van Knapen, F., Wakelin, D. (Eds.), Trichinellosis, vol. 9. Centro de Investigacion y Estudios Avanzados IPN, D.F. Mexico, Mexico, pp. 43-46.

Zarlenga, D.S., Aschenbrenner, R.A., Lichtenfels, J.R., 1996. Variations in microsatellite sequences provide evidence for population differences and multiple ribosomal gene repeats within Trichinella pseudospiralis. J. Parasitol. 82, 534-538.

Zarlenga, D.S., Chute, M.B., Martin, A., Kapel, C.M., 1999. A multiplex PCR for unequivocal differentiation of all encapsulated and nonencapsulated genotypes of Trichinella. Int. J. Parasitol. 29, 1859-1867.

Zarlenga, D.S., Rosenthal, B.M., La Rosa, G., Pozio, E., Hoberg, E.P., 2006. PostMiocene expansion, colonization, and host switching drove speciation among extant nematodes of the archaic genus Trichinella. Proc. Natl. Acad. Sci. USA 103, 7354-7359.

Zarlenga, D.S., Rosenthal, B., Hoberg, E., Mitreva, M., 2009. Integrating genomics and phylogenetics in understanding the history of Trichinella species. Vet. Parasitol. 159, 210-213.

Zimmerman, W.J., Hubbard, E.D., Mathews, J., 1959. Studies on fecal transmission of Trichinella spiralis. J. Parasitol. 45, 441-445. 